\title{
Mycoplasma bovis-generated reactive oxygen species and induced apoptosis in bovine mammary epithelial cell cultures
}

\author{
Yang Liu, ${ }^{1}$ Man Zhou, ${ }^{1}$ Siyu Xu, ${ }^{1}$ Muhammad Asfandyar Khan, ${ }^{1}$ Yuxiang Shi, ${ }^{1}$ Weijie Qu, ${ }^{2}$ Jian Gao, ${ }^{1}$ \\ Gang Liu, ${ }^{1}$ John P. Kastelic, ${ }^{3}$ and Bo Han ${ }^{1 *}$ \\ ${ }^{1}$ Department of Clinical Veterinary Medicine, College of Veterinary Medicine, China Agricultural University, Beijing 100193, China \\ ${ }^{2}$ College of Veterinary Medicine, Yunnan Agricultural University, Kunming 650201, China \\ ${ }^{3}$ Department of Production Animal Health, Faculty of Veterinary Medicine, University of Calgary, Calgary, AB, Canada, T2N 4N1
}

\section{ABSTRACT}

Mycoplasma bovis is an important cause of bovine mastitis in China and worldwide. We hypothesized that $M$. bovis damages bovine mammary epithelial cells (bMEC), with the degree of damage varying among field isolates. Our objective was to evaluate 2 novel sequence type (ST) field strains of M. bovis (ST172 and ST173) for their ability to induce oxidative stress, cytotoxicity, pathomorphological changes, and apoptosis in bMEC, as a model for pathogenesis of $M$. bovis-induced bovine mastitis. Cytotoxicity (as indicated by release of lactate dehydrogenase, LDH) from bMEC depended on multiplicity of infection (MOI), with a high MOI $(1: 1,000)$ being required to induce cytotoxicity. Morphological changes in bMEC, including shrinkage, loss of cell integrity, and heavy staining (hematoxylin and eosin) of cytoplasm were apparent $24 \mathrm{~h}$ after infection with ST172 or ST173 M. bovis, with more severe changes being induced by the latter strain. Adhesion and invasion assays both had curvilinear patterns, peaking $12 \mathrm{~h}$ after infection with MOI of 1:1,000. Both production of reactive oxygen species (ROS) and proportion of apoptotic cells increased with time after infection. Increased Bax/Bcl-2 ratios and activation of caspase-3 implied involvement of mitochondria-dependent pathways of apoptosis. Furthermore, intracellular ROS generation, apoptosis, and cleaved caspase-3 were mitigated by $N$-acetyl-L-cysteine, a ROS scavenger. Both interleukin (IL)-1 $\beta$ and IL-6 were significantly upregulated by ST172 and ST173 M. bovis, with little change in expression of tumor necrosis factor- $\alpha$. One ST173 M. bovis isolate had the greatest cytotoxicity of all of our field isolates, with the highest LDH release,

Received March 27, 2020.

Accepted July 2, 2020.

*Corresponding author: hanbo@cau.edu.cn adhesion, invasion, ROS production, and apoptosis. In conclusion, our hypothesis was supported: M. bovis damaged bMEC by generating ROS and initiating a mitochondria-dependent pathway of apoptosis, with the degree of damage varying among field isolates. This study provided new knowledge regarding pathogenesis of $M$. bovis-induced bovine mastitis.

Key words: Mycoplasma bovis, bovine mastitis, reactive oxygen species (ROS), apoptosis, bovine mammary epithelial cells

\section{INTRODUCTION}

Mastitis is the most frequent and costly disease of dairy cattle worldwide (Ruegg, 2017). Mycoplasma bovis causes bovine mastitis in intensive dairies in many countries, including China (Fox, 2012; Nicholas et al., 2016; Liu et al., 2020). Despite the prevalence and importance of $M$. bovis, inadequate understanding regarding pathogenesis of $M$. bovis mastitis has hindered development of control strategies (Calcutt et al., 2018).

Whole-genome sequencing of $M$. bovis has identified some virulent factors, including adhesion, $\mathrm{H}_{2} \mathrm{O}_{2}$ generation, nucleases, and formation of biofilm (Calcutt et al., 2018). However, interactions between M. bovis and host cells are not well characterized. Responses to $M$. bovis infection differed among host cells. For example, M. bovis can inhibit peripheral blood mononuclear cell proliferation (van der Merwe et al., 2010) and induce apoptosis in various bovine cells, including lymphocytes (Vanden Bush and Rosenbusch, 2002), embryonic turbinate cells (Josi et al., 2018), and neutrophils (Jimbo et al., 2017), as well as delay apoptosis in macrophages (Maina et al., 2019). In a previous study, 2 M. bovis strains did not induce apoptosis and cytotoxicity in bovine mammary epithelial cells (bMEC) at multiplicities of infection (MOI) ranging from 1:1.3 to 1:9 (Josi et al., 2018). However, it was unclear whether apoptosis- and cytotoxicity-inducing capacities of $M$. bovis were dependent on the MOI. 
Oxidative stress, triggered by various infections, has many consequences, including deleterious effects on milk production and lactation length in dairy cattle (Guo et al., 2020). In cattle with M. bovis pneumonia, production of hydrogen peroxide and free oxygen radicals contributed to formation of caseo-necrotic lesions (Schott et al., 2014). Furthermore, there were variations among $M$. bovis isolates regarding their ability to induce production of reactive oxygen species (ROS) in bovine leukocytes (Wiggins et al., 2011). Although the role of $M$. bovis-induced oxidative stress has been characterized in acute and chronic infections, its effects on bMEC have not been well characterized. We hypothesized that $M$. bovis damages bMEC, with the degree of damage varying among field isolates. Using in vitro-cultured bMEC as a model for pathogenesis of $M$. bovis-induced bovine mastitis, objectives of this study were to (1) explore patterns and causes of cell damage and death; and (2) compare capacity of 2 field isolates and 1 typical PG45 strain to induce cell damage.

\section{MATERIALS AND METHODS}

\section{Ethics Statement}

This study was conducted in accordance with ethical guidelines of China Agricultural University (Beijing, China). Prior to start of the study, ethical approval was granted by the Departmental Committee of the College of Veterinary Medicine, China Agricultural University.

\section{Milk Sample Collection and M. bovis Isolation}

A total of 476 milk samples, including 450 clinical mastitis (CM) samples and 26 bulk tank milk (BTM) samples, were collected from 23 dairy farms (each farm had >1,000 lactating cows) from August 2018 to September 2019 from 10 provinces in China (Supplemental Table S1; https://doi.org/10.3168/jds.2020-18599). The CM samples were collected aseptically into $50-\mathrm{mL}$ tubes after a diagnosis of mastitis was made, based on clinical signs, including presence of abnormal and discolored secretions or abnormal udders (NMC, 2017), whereas BTM samples were collected from bulk tanks after milking. All milk samples were collected into $50-\mathrm{mL}$ sterile bottles that were refrigerated and subsequently transported to our mastitis reference laboratory on ice for culture, identification, and antibiotic susceptibility testing, as described (Liu et al., 2015, 2020). All M. bovis strains were identified and sequenced as belonging to 3 sequence types (ST): ST10, ST172, and ST173 (Liu et al., 2020), with all strains recovered and purified as described previously (Bürki et al., 2015). In brief, multilocus sequence typing (MLST) was performed according to the PubMLST reference method (Register et al., 2020). Seven housekeeping genes, dnaA, gltX, gps A, gyrB, pta-2, tdk, and tkt, were amplified from genomic DNA of each $M$. bovis isolate, followed by sequencing. Allelic profiles and ST of the M. bovis isolates were identified on the basis of output from sequence queries of the PubMLST M. bovis Locus/sequence Definitions Database (https://pubmlst.org/bigsdb?db =pubmlst_mbovis_seqdef). To prepare Eaton's broth, first, PPLO basic broth was made by dissolving $21 \mathrm{~g}$ of Difco PPLO medium (BD Biosciences, San Jose, CA) and $2.5 \mathrm{~g}$ of yeast extract (BD Biosciences) in $700 \mathrm{~mL}$ of ultrapure water, then autoclaving it at $121^{\circ} \mathrm{C}$ for 30 min. Eaton's broth was PPLO basic broth plus 200 $\mathrm{mL}$ of horse serum (Hyclone Laboratories, Logan UT) and $100 \mathrm{~mL}$ of additive. The additive was prepared by dissolving $10 \mathrm{~g}$ of glucose, $0.5 \mathrm{~mL}$ of penicillin $(200,000$ $\mathrm{IU} / \mathrm{mL})$, and $12.5 \mathrm{~mL}$ of phenol red $(0.5 \%)$ in ultrapure water (final volume, $100 \mathrm{~mL}$ ) and then sterilizing it by filtration through a $0.22-\mu \mathrm{m}$ filter. After Eaton's broth was prepared, the $\mathrm{pH}$ was adjusted to 7.6 to 7.8. Eaton's plates were made as follows: $700 \mathrm{~mL}$ of PPLO basic broth with $7.5 \mathrm{~g}$ of agar (Oxoid), prepared as described above. After autoclaving at $121^{\circ} \mathrm{C}$ for $30 \mathrm{~min}$, PPLO basic broth with agar was cooled and held at $50^{\circ} \mathrm{C}$ to prevent solidification; then, PPLO broth was supplemented with $200 \mathrm{~mL}$ of horse serum (Hyclone) and $100 \mathrm{~mL}$ of additive prepared as described above (except without phenol red). Finally, $20 \mathrm{~mL}$ of the completed medium with agar was poured into a $90-\mathrm{mm}$ Petri dish. All strains, including the type strain PG45, were inoculated into $3 \mathrm{~mL}$ of Eaton's broth (ratio of $1: 100, \mathrm{vol} / \mathrm{vol}$ ) and incubated at $37^{\circ} \mathrm{C}$ in a humidified atmosphere with $5 \% \mathrm{CO}_{2}$ for 48 to $72 \mathrm{~h}$, until color changed in the inoculated medium. Then, a culture of each strain was recovered and stored at 2 to $8^{\circ} \mathrm{C}$. For all strains, the number of passages was $\leq 12$. For each strain, counts (cfu) were determined by performing 10fold serial dilutions in PBS with subsequent spotting on Eaton's plates (Bürki et al., 2015). Specifically, 1 $\mathrm{mL}$ of each mycoplasma culture was added to $9 \mathrm{~mL}$ of PBS, followed by mixing thoroughly by vortexing for 5 s. For each strain, 10 -fold dilutions $\left(10^{-2}\right.$ to $\left.10^{-9}\right)$ were prepared in $0.9-\mathrm{mL}$ volumes. Then, $10 \mu \mathrm{L}$ of each prepared dilution was spotted on Eaton's plates, followed by incubation at $37^{\circ} \mathrm{C}$ in a humidified atmosphere with $5 \% \mathrm{CO}_{2}$ for $48 \mathrm{~h}$, or as long as single colonies with the typical "fried egg" appearance were visible microscopically (at $40 \times$ magnification). For each original culture, counts were determined based on average values from 
assessment on spotted plates and dilutions (the latter were each counted 4 times).

\section{Cell Culture}

A bMEC line (MAC-T; Jingma Biological Technology Co. Ltd., Shanghai, China) derived from a cow was cultured in Dulbecco's modified Eagle medium (DMEM; HyClone Laboratories) supplemented with $10 \%$ fetal bovine serum (Gibco, Grand Island, NY) in a $25-\mathrm{cm}^{2}$ flask (Corning Inc., Corning, NY) incubated in $5 \% \mathrm{CO}_{2}$ at $37^{\circ} \mathrm{C}$. When cells reached 60 to $70 \%$ confluence, they were subcultured. Cells were dispersed with PBS supplemented with $0.25 \%$ trypsin, the cell concentration was adjusted to $1 \times 10^{5}$ cells $/ \mathrm{mL}$, and cells were then routinely seeded $(0.1,0.5,2$, or $5 \mathrm{~mL}$ in $96-$, $24-$, or 6 -well plates or $25-\mathrm{cm}^{2}$ flasks, respectively) and incubated for $24 \mathrm{~h}$ in $5 \% \mathrm{CO}_{2}$ at $37^{\circ} \mathrm{C}$ before conducting experiments.

\section{Cell Infections}

Before infection, bMEC in a well were stained with 0.4\% trypan blue (Beyotime Biotechnology, Beijing, China) and enumerated with a cell counter. The $M$. bovis cultures were centrifuged for $15 \mathrm{~min}$ at 5,900 $\times \mathrm{g}$, washed once in sterile PBS at $\mathrm{pH} 7.5$, and resuspended in DMEM supplemented with $4 \%$ fetal bovine serum, with concentrations adjusted to achieve various MOI (stated in the following individual assays). The MOI was defined as the ratio of added mycoplasma and host cells. The counts of mycoplasma inoculum were confirmed after growth on Eaton's plates.

\section{Lactate Dehydrogenase}

To characterize lactate dehydrogenase $(\mathbf{L D H})$ released from bMEC infected by $M$. bovis (as a measure of cytotoxicity), 1 isolate each, identified as the NMH7 ST173 strain and the type PG45 ST17 strain, was used for infection at various time points and MOIs. To determine LDH release patterns at various MOIs, bMEC were seeded in 96-well plates incubated in $5 \% \mathrm{CO}_{2}$ at $37^{\circ} \mathrm{C}$ for $24 \mathrm{~h}$ before infection. Then, inocula of each isolate were prepared, as described above, at MOI of 1:10, 1:100, and 1:1,000. Inocula were added to wells (0.1 $\mathrm{mL} /$ well) after the spent medium was discarded. Plates were incubated at $5 \% \mathrm{CO}_{2}$ at $37^{\circ} \mathrm{C}$. At $24 \mathrm{~h}$ postinfection (hpi), the supernatant of each well was collected as a sample and LDH concentrations were measured using an LDH detecting kit (Beyotime Biotechnology), according to the manufacturer's instructions. Then, the MOI yielding the highest LDH concentration was selected for the infection model.

To determine $\mathrm{LDH}$ release at various time points, bMEC were infected at the selected MOI yielding the highest LDH concentrations. Supernatants of wells were collected separately at $3,6,12$, and 24 hpi as samples to detect LDH concentrations. Then, the time point yielding the highest LDH concentrations was selected for the infection model.

To determine differences among strains in their propensity to cause cell damage, 3 representative isolates of each sequence type (ST173, ST172, and ST10) were selected randomly among isolates within each sequence type. In addition, $M$. bovis ST17 PG45 strain was used as a reference. Then, the capability of isolates to induce LDH release from bMEC was compared among ST groups (ST173, ST172, and ST10) at the MOI and time selected. One isolate was randomly selected in the highest LDH release ST group, whereas another was randomly selected in the lowest LDH release ST group to perform the following tests. The assay was repeated 3 times independently.

\section{Bacterial Adhesion}

Two selected isolates were tested and M. bovis strain PG45 was used as a reference control. First, adhesion of each strain was determined. Briefly, bMEC were seeded in 24-well plates that were incubated in $5 \% \mathrm{CO}_{2}$ at $37^{\circ} \mathrm{C}$ for $24 \mathrm{~h}$ before infection. Inocula of each isolate were prepared, as described above, for MOI of 1:10 and 1:1,000 separately. Before infection, cells were washed once with PBS and blocked for 15 min with $0.1 \%$ BSA (Sigma Aldrich, St. Louis, MO) in PBS, followed by an additional wash with PBS. Then, PBS in wells was discarded, inocula added $(0.5 \mathrm{~mL} /$ well $)$, and plates incubated in $5 \% \mathrm{CO}_{2}$ at $37^{\circ} \mathrm{C}$. At $3,6,12$, and $24 \mathrm{hpi}$, liquid in the wells was discarded and wells were washed 3 times with PBS. A 23-gauge needle and syringe were used to remove and disrupt cells, with bottoms of wells examined with a microscope to verify that most cells had been removed. The lysate of removed cells, along with the adherent $M$. bovis, was resuspended in $0.5 \mathrm{~mL}$ of PBS and lysed mechanically with needles and syringes (Josi et al., 2018). Lysates were used as samples to verify adherent $M$. bovis per well. The counts (cfu) of each well were verified by plating on Eaton's plates after 10-fold serial dilutions in PBS. This assay was also done with the same $3 \mathrm{M}$. bovis strains without bMEC to confirm ability of $M$. bovis to grow and survive in DMEM. The adhesion assay was repeated 3 times independently. Percentage of adherent M. bovis 
was expressed relative to the initial number of $M$. bovis in the inocula.

\section{Bacterial Invasion}

Various concentrations of gentamicin sulfate were tested for their ability to kill $3 \mathrm{M}$. bovis strains within 3 h (Supplemental Figure S1; https://doi.org/10.3168/ jds.2020-18599). Then, invasion of each strain was determined. Briefly, bMEC were seeded in 24-well plates that were incubated in $5 \% \mathrm{CO}_{2}$ at $37^{\circ} \mathrm{C}$ for $24 \mathrm{~h}$ before infection. Inocula of each isolate were prepared, as described above, for MOI of 1:10 and 1:1,000 separately. Before infection, cells were washed once with PBS, which was discarded, and then inocula were added $(0.5$ $\mathrm{mL} /$ well) and plates incubated at $5 \% \mathrm{CO}_{2}$ at $37^{\circ} \mathrm{C}$. At $3,6,12$, and $24 \mathrm{hpi}$, liquid in wells was discarded and wells were washed 3 times with PBS. Then, wells were incubated with DMEM supplemented with $400 \mu \mathrm{g} / \mathrm{mL}$ inocula (corresponding to MOI of 1:10) or $1,600 \mu \mathrm{g} /$ $\mathrm{mL}$ (corresponding to MOI of 1:1,000). Plates were incubated in $5 \% \mathrm{CO}_{2}$ at $37^{\circ} \mathrm{C}$ for $3 \mathrm{~h}$ to kill extracellular mycoplasma. Then, wells were washed 3 times with PBS, cells were collected, and counts determined as described above. As a control for efficacy of gentamicin sulfate for killing mycoplasma, inocula were incubated in Eppendorf tubes under the same conditions (without bMEC) and gentamicin sulfate solution was added. After incubation, mycoplasma were centrifuged at 5,900 $\times g$ for $15 \mathrm{~min}$, followed by 2 PBS washes. Then, mycoplasma were resuspended and counts determined. The invasion assay was repeated 3 times independently.

\section{Hematoxylin and Eosin Staining}

The bMEC were seeded on glass coverslips on 6 -well plates and incubated in $5 \% \mathrm{CO}_{2}$ at $37^{\circ} \mathrm{C}$ for $24 \mathrm{~h}$ before infection. Before infection, cells were washed once with PBS. Inocula of each isolate were prepared as described above and cells were infected at MOI of 1:1,000 for each strain. Then, cells were incubated in $5 \% \mathrm{CO}_{2}$ at $37^{\circ} \mathrm{C}$. Sampling was done at $3,6,12$, and 24 hpi. Cells on coverslips were fixed in formaldehyde fixing solution (Beyotime Biotechnology) for $15 \mathrm{~min}$. Then, coverslips were washed twice with distilled water and stained with hematoxylin (Beyotime Biotechnology) for 5 min. Thereafter, they were bleached with tap water for 10 min, and washed with distilled water. Then, coverslips were stained with eosin (Beyotime Biotechnology) for 2 min, followed by 2 washes with $70 \%$ ethanol. Coverslips were dehydrated in the following alcohol series: 70, 80, and $90 \%$ ethanol and absolute ethyl alcohol, $10 \mathrm{~s}$ in each concentration, and then treated with xylene for 5 min. Finally, cells in randomly selected fields were ex- amined under an optical microscope (Olympus, Tokyo, Japan) at 100-fold magnification. Cells in each well were quantified by counting the average number of cells in randomly selected 5 fields per sample for each strain at $0,6,12$, and $24 \mathrm{hpi}$ at $100 \times$ magnification.

\section{Measurement of Intracellular ROS}

Infections were performed as described above at MOI 1:1,000 and sampling performed 3, 6, 12 and 24 hpi. Cells were washed with PBS, collected after digestion with $0.25 \%$ trypsin without EDTA, stained with 2'-7'dichlorofluorescin diacetate (DCFH-DA, $5 \mu \mathrm{mol} / \mathrm{L}$; Beyotime Biotechnology) for $20 \mathrm{~min}$ and washed 3 times with DMEM. Then, bMEC treated with $\mathrm{H}_{2} \mathrm{O}_{2}(500 \mu M)$ for $24 \mathrm{~h}$ in $5 \% \mathrm{CO}_{2}$ at $37^{\circ} \mathrm{C}$ were used as the positive control. Finally, cells were assessed using a flow cytometer (FACS Calibur, BD Biosciences, Franklin Lakes, NJ; Gu et al., 2019). Approximately $1 \times 10^{4}$ events were captured for each sample by the FACS Calibur flow cytometer at an excitation of 488 $\mathrm{nm}$ and emission of $520 \mathrm{~nm}$. The percentage of distribution of cell apoptosis was analyzed by CellQuest software (BD Biosciences). Various subpopulations were distinguished using 2 criteria: $\mathrm{R} 1$, the percentage of DCFH-DA-negative cells, and R2, the percentage of DCFH-DA-positive cells.

\section{Apoptosis Analysis}

Apoptosis was detected using flow cytometry. Infection at MOI of 1:1,000 was performed as described for LDH. Sampling was done at 6, 12, and 24 hpi. First, cells were washed once with PBS, then digested with $0.25 \%$ trypsin without EDTA; digestion was stopped by adding spent medium into original wells. Then, fluid was decanted from the wells and cells collected by centrifuging at $1,000 \times g$ for $10 \mathrm{~min}$. Cells were washed twice with precooled $\left(4^{\circ} \mathrm{C}\right) \mathrm{PBS}$ and stained with an annexin V-fluorescein isothiocyanate (FITC) apoptosis detection kit (Beyotime Biotechnology). The bMEC treated with $\mathrm{H}_{2} \mathrm{O}_{2}(500 \mu M)$ for $24 \mathrm{~h}$ in $5 \% \mathrm{CO}_{2}$ at $37^{\circ} \mathrm{C}$ were used as the positive control. Approximately $1 \times$ $10^{4}$ events were captured for each sample by a FACS Calibur flow cytometer (BD Biosciences; Gu et al., 2019). The percentage of distribution of cell apoptosis was analyzed by CellQuest software (BD Biosciences). Subpopulations were distinguished using the following criteria: Q1, the percentage of annexin V-negative, PIpositive cells (i.e., necrotic cells); Q2, the percentage of annexin V/PI double-positive cells (i.e., late apoptotic cells); Q3, the percentage of annexin V-positive, PInegative cells (i.e., early apoptotic cells); and Q4, the percentage of annexin V/PI double-negative cells (i.e., 
live cells). Apoptosis proportion was determined as the sum of Q2 + Q3.

\section{Western Blot}

The bMEC were infected as described above at an MOI of 1:1,000. Sampling was performed at 3, 6, 12, and $24 \mathrm{hpi}$. Total protein was extracted with radioimmunoprecipitation assay (RIPA) lysis buffer (Beyotime Biotechnology), with all extractions performed on ice. All protein samples were supplemented with $1 \mathrm{mM}$ phenylmethylsulfonyl fluoride (Beyotime Biotechnology), protease inhibitor cocktail (Beyotime Biotechnology), and phosphatase inhibitor (Beyotime Biotechnology). Protein concentrations were determined with a bicinchoninic acid protein assay kit (Beyotime Biotechnology), according to the manufacturer's instructions. For each sample, equal amounts of protein were separated by SDS-PAGE. Subsequently, proteins were transferred onto a polyvinylidene difluoride membrane (PVDF, Millipore, Bedford, MA) that was first blocked with 5\% skim milk in Tween-20/TBS (TBST) at room temperature for $2 \mathrm{~h}$, followed by 3 washes in TBST for 10 min each; then, membranes were incubated with each specific primary antibody (all from ProteinTech Group, Rosemont, IL), including Bax (50599-2-Ap), Bcl-2 (12789-1-Ap), $\beta$-actin (66009-1-Ig), caspase-3 (19677-1-Ap) and glyceraldehyde-3-phosphate dehydrogenase (GAPDH, 10494-1-Ap) separately overnight at $4^{\circ} \mathrm{C}$. Thereafter, membranes were probed with horseradish peroxidase-conjugated secondary antibody (Proteintech Group) for $1 \mathrm{~h}$ at room temperature, followed by 3 washes as described above. Membranes were treated with an enhanced chemiluminescence system (ECL, Beyotime Biotechnology). Expression of Bax and $\mathrm{Bcl}-2$ was normalized to that of $\beta$-actin, whereas expression of cleaved caspase 3 was normalized to that of GAPDH. Band density was analyzed with Image J (National Institutes of Health, Bethesda, MD).

\section{RNA Extraction, cDNA Synthesis, and Real-Time PCR}

At the time points indicated, bMEC infected at MOI $=1: 1,000$ were harvested using $1 \mathrm{~mL}$ of TransZol Up lysis solution (TransGen Biotech, Beijing, China). Total RNA was extracted with a total RNA extraction kit (TransGen Biotech), according to manufacturer's instructions. The cDNA was synthesized using TransScript II All-in-One First-Strand cDNA Synthesis SuperMix for PCR (TransGen Biotech). Both RNA and cDNA were quantified with a NanoDrop One spectrophotometer (Thermo Fisher Scientific, Waltham, MA).

The mRNA expression levels of IL1B, IL6, TNFA, and $I L 8$ were verified with real-time PCR; GAPDH was used as a reference gene. Primers used (Table 1) were based on previous reports (Zbinden et al., 2015; Shahid et al., 2020). The real-time quantitative (q)PCR assay was performed starting with predenaturation at $94^{\circ} \mathrm{C}$ for $2 \mathrm{~min}$, followed by 40 cycles of denaturation at $95^{\circ} \mathrm{C}$ for $5 \mathrm{~s}$, and annealing at $60^{\circ} \mathrm{C}$ for $60 \mathrm{~s}$ using Applied Biosystems StepOnePlus Real Time PCR system (Thermo Fisher Scientific). Melt curve analysis consisted of heating PCR products from 55 to $95^{\circ} \mathrm{C}$, with fluorescence signal checked every $0.5^{\circ} \mathrm{C}$ to verify specificity of each pair of primers. Cycle threshold (Ct) values were determined by the StepOne Software version 2.3 (ThermoFisher Scientific), where $\Delta \mathrm{Ct}=\mathrm{Ct}$ target gene - Ct endogenous control (arithmetic mean of the reference gene), and $\Delta \Delta \mathrm{Ct}=\Delta \mathrm{Ct}$ sample $\Delta \mathrm{Ct}$ control (uninfected cells). To visualize effects of $M$. bovis on response of target genes in bMEC, relative mRNA expression data were presented as $2^{-\Delta \Delta \mathrm{Ct}}$, using $G A P D H$ as the reference gene.

\section{ROS Scavenger Treatment}

$N$-Acetyl-L-cysteine (NAC, Sigma-Aldrich) was used as a ROS scavenger. For this, bMEC were pretreated

Table 1. Primer sequences of bovine genes used for quantitative PCR

\begin{tabular}{llll}
\hline \multirow{2}{*}{ Gene } & Primer sequence & & Reference \\
\hline TNFA & Upstream & 5'-ACGGGCTTTACCTCATCTACTC & Shahid et al., 2020 \\
& Downstream & 3'-GCTCTTGATGGCAGACAGG & \\
IL1B & Upstream & 5'-AGGTGGTGTCGGTCATCGT & Shahid et al., 2020 \\
& Downstream & 3'-GCTCTCTGTCCTGGAGTTGC & \\
& Upstream & 5'-ACACATTCCACACCTTTCCA & Shahid et al., 2020 \\
& Downstream & 3'-GGTTTAGGCAGACCTCGTTT & \\
& Upstream & 5'-ATCAGAACACTGATCCAGATCC & Zbinden et al., 2015 \\
GAPDH & Downstream & 3'-CAAGGTTTCTCAGGATGAGG & \multirow{2}{*}{ Shahid et al., 2020 } \\
& Upstream & 5'-CATTGACCTTCACTACATGGT & \\
& Downstream & 3'-ACCCTTCAAGTGAGCCCAG & \\
\hline
\end{tabular}


with DMEM supplemented with $10 \mathrm{~m} M$ NAC for 3 $\mathrm{h}$ before infection by type strain ST17 PG45, ST173 NMH7, and ST172 ShaanxiBTM01 at MOI of 1:1,000. At $24 \mathrm{hpi}$, samples were collected and ROS and apoptosis assays performed as described above. Western blotting was done to detect changes in expression of cleaved caspase-3 for the type strain PG45 and a field isolate. Band density was analyzed with Image J (National Institutes of Health).

\section{Statistical Analyses}

Data are mean \pm standard deviation of 3 independent experiments. All data were analyzed by 1 -way ANOVA, followed by post hoc testing using Bonferroni correction for multiple comparisons, using SPSS 22.0 (IBM Corp., Armonk, NY). Data designated as independent variables in the model were as follows: treatments (uninfected control cells, infections at various MOIs, time points or by isolates with different ST) in the LDH assays; treatments (infections by different isolates) in adhesion assays and invasion assays; treatments (uninfected control cells, infections by different isolates) in HE assays, ROS measurement assays, apoptosis assays, Western blotting assays, and in quantitative real-time PCR assays.

\section{RESULTS}

\section{Cytotoxicity in bMEC Induced by M. bovis Infection}

The $M$. bovis ST173 NMH7 strain and type ST17 PG45 strain were selected to assess LDH release patterns of bMEC after infection (Figure 1A). Release of $\mathrm{LDH}$ at $24 \mathrm{hpi}$ was significantly greater from the infected group (MOI of 1:1,000) compared with control cells $(P=0.001$ for ST17 PG45; $P<0.001$ for ST173 NMH7); however, there was no significant change at MOI of $1: 10$ or $1: 100$. An MOI of $1: 1,000$ was selected to explore $\mathrm{LDH}$ release at various time points. Compared with control group and related to each time point, we detected significant increases in LDH at 12 and $24 \mathrm{~h}$ in bMEC infected by ST173 NMH7 $(P<0.001$ for $12 \mathrm{~h}$ and $24 \mathrm{~h})$ and at $24 \mathrm{~h}$ in bMEC infected by PG45 ( $P=0.02$ for $24 \mathrm{~h}$; Figure 1B). Comparisons among isolates for ability to damage bMECs were done at MOI of 1:1000 and at 24 hpi. Randomly selected isolates included NMH7, NMH10, HBCB01, ShaanxiBTM01, HBBDBTM, HBLFBTM01, HBXTBTM, JZBTM, and SD1901 (Table 2). The IDs of the $M$. bovis strains in this study were downloaded from the MLST database (https://pubmlst.org/mbovis/) and are listed in Supplemental Table S2 (https://doi .org/10.3168/jds.2020-18599). All isolates significantly increased LDH compared with the control group ( $P$ $<0.05$; Table 2). However, the extent of induced cell damage varied among isolates. Based on post hoc testing, isolates in ST173 caused significantly greater LDH release than did isolates of ST172 or ST10 $(P=0.001$ for ST173 vs. ST172; $P<0.001$ for ST173 vs. ST10), whereas isolates of ST172 did not differ from those with ST10. Consequently, strains ST173 NMH7 and ST172 ShaanxiBTM01 were randomly selected to perform the following tests. Regarding counts of inocula prepared for LDH assays, concentrations of $M$. bovis in inocula at MOI of $1: 1,000$ were $3.40 \pm 1.06 \times 10^{8} \mathrm{cfu} / \mathrm{mL}$ for PG45, $3.13 \pm 1.58 \times 10^{8} \mathrm{cfu} / \mathrm{mL}$ for NMH7, $3.96 \pm$ $1.23 \times 10^{8} \mathrm{cfu} / \mathrm{mL}$ for NMH10, $3.01 \pm 1.73 \times 10^{8} \mathrm{cfu} /$ $\mathrm{mL}$ for HBCB01, $3.45 \pm 1.45 \times 10^{8} \mathrm{cfu} / \mathrm{mL}$ for ShaanxiBTM01, $4.35 \pm 1.70 \times 10^{8} \mathrm{cfu} / \mathrm{mL}$ for HBBDBTM, $3.14 \pm 1.62 \times 10^{8} \mathrm{cfu} / \mathrm{mL}$ for HBLFBTM01, $4.25 \pm$ $1.52 \times 10^{8} \mathrm{cfu} / \mathrm{mL}$ for HBXTBTM, $3.72 \pm 2.08 \times 10^{8}$ $\mathrm{cfu} / \mathrm{mL}$ for JZBTM, and $3.51 \pm 1.45 \times 10^{8} \mathrm{cfu} / \mathrm{mL}$ for SD1901. There was no significant difference among isolates in inocula counts (based on 1-way ANOVA test, with isolates selected as independent variables in the statistical model). For inocula related to MOI of 1:100, the counts were $3.73 \pm 1.80 \times 10^{7} \mathrm{cfu} / \mathrm{mL}$ for PG45 and $4.49 \pm 1.13 \times 10^{7} \mathrm{cfu} / \mathrm{mL}$ for NMH7. For inocula related to MOI of 1:10, the counts were $3.20 \pm 1.47 \times$ $10^{6} \mathrm{cfu} / \mathrm{mL}$ for PG45 and $3.57 \pm 2.39 \times 10^{6} \mathrm{cfu} / \mathrm{mL}$ for NMH7.

\section{Adhesion and Invasion}

Strains ST173 NMH7, ST172 ShaanxiBTM01, and ST17 PG45 were used to determine survival and growth patterns. At $\mathrm{MOI}=1: 10$ (Figure $2 \mathrm{~A}$ ), the numbers of $M$. bovis in medium were stable at 3,6 , and $12 \mathrm{hpi}$, irrespective of the presence or absence of bMEC. However, at $24 \mathrm{hpi}$, numbers decreased significantly in DMEM when bMEC were absent, but increased 30 to 100 times when mycoplasma were cocultured with bMEC. At $\mathrm{MOI}=1: 1,000$ (Figure 2B), numbers of $M$. bovis in medium were stable at 3 and $6 \mathrm{hpi}$, irrespective of the presence or absence of bMEC. However, there was a significant decrease in counts between wells without and with bMEC at 12 and 24 hpi. Numbers of $M$. bovis decreased significantly in DMEM without cells, whereas at $12 \mathrm{hpi}$, numbers increased marginally compared with that of the initial inocula. Adhesion assay results are shown in Figure 3A to D. Percentage of adherent $M$. bovis increased with duration of infection. There was a continuous increase in count of adherent $M$. bovis at MOI of 1:10 (Figure 3A), whereas at MOI of 1:1,000, counts of adherent $M$. bovis increased, peaked at $12 \mathrm{~h}$, and then decreased at $24 \mathrm{~h}$ (Figure 3B). There were relatively lower percentages of adherent M. bovis (Fig- 


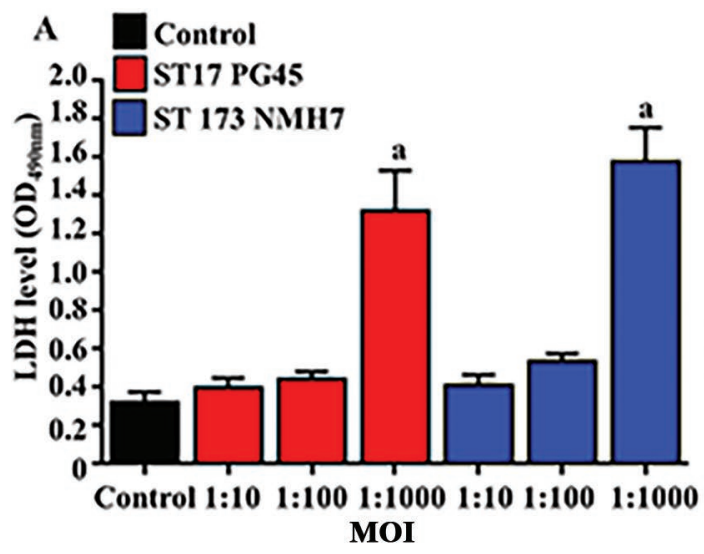

B

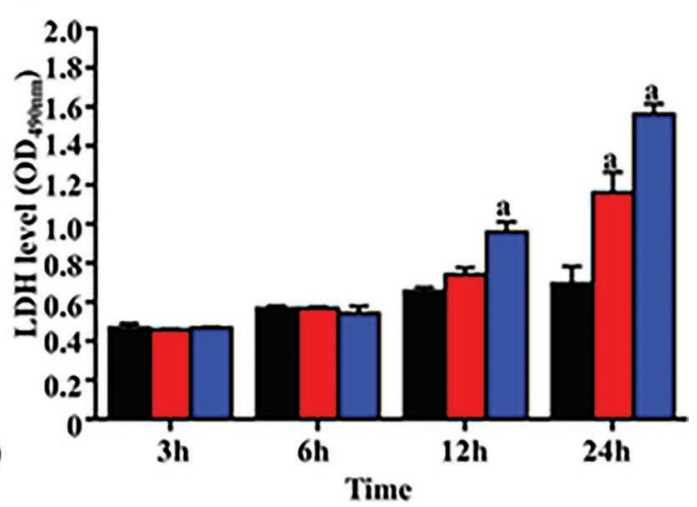

Figure 1. Release of lactate dehydrogenase (LDH) from bovine mammary epithelial cells (bMEC) infected with Mycoplasma bovis. (A) LDH released from bMEC $24 \mathrm{~h}$ after infection by $M$. bovis at various multiplicities of infection (MOI); (B) LDH released from bMEC at 3 to $24 \mathrm{~h}$ postinfection with $M$. bovis at an MOI of 1:1,000. Data are mean \pm SD of 3 independent experiments. Bars with a letter (a) differed compared with the control group $(P<0.05)$. $\mathrm{OD}_{490 \mathrm{~nm}}=$ optical density at $490 \mathrm{~nm}$.

ure 3D) but higher counts of adherent $M$. bovis (Figure 3B) at an MOI of 1:1,000 compared with an MOI of 1:10 (Figure 3A and C). Strain ST173 NMH7 induced a significantly higher percentage of adherent $M$. bovis than the other 2 strains (Figure $3 \mathrm{C}$ and D) at 6 hpi. There was a continuous increase in invasive counts for an MOI of $1: 10$ at $24 \mathrm{~h}$, but at an MOI of 1:1000, invasive counts increased, peaked at $12 \mathrm{~h}$, and subsequently decreased at $24 \mathrm{~h}$ (Figure $3 \mathrm{E}$ and F). Furthermore, ST173 NMH7 had significantly higher cellular invasion than the other 2 strains at all times points except for 24 hpi at an MOI of 1:1,000. Concentrations of $M$. bovis in inocula prepared in the adhesion and invasion assays at an MOI of 1:1,000 were $2.69 \pm 1.62 \times 10^{8} \mathrm{cfu} / \mathrm{mL}$ for $\mathrm{PG} 45,3.73 \pm 2.01 \times 10^{8} \mathrm{cfu} / \mathrm{mL}$ for NMH7, and $2.89 \pm$ $1.50 \times 10^{8} \mathrm{cfu} / \mathrm{mL}$ for ShaanxiBTM01. Concentrations of $M$. bovis in inocula prepared for adhesion and invasion assays at an MOI of 1:10 were $3.90 \pm 0.99 \times 10^{6}$ $\mathrm{cfu} / \mathrm{mL}$ for $\mathrm{PG} 45,3.67 \pm 1.89 \times 10^{6} \mathrm{cfu} / \mathrm{mL}$ for $\mathrm{NMH} 7$, and $3.12 \pm 1.45 \times 10^{6} \mathrm{cfu} / \mathrm{mL}$ for ShaanxiBTM01.

\section{Morphological Changes in bMEC}

Morphological changes in bMEC were assessed by optical microscopy after hematoxylin and eosin $(\mathbf{H E})$ staining. Control cells did not have any apparent changes. In contrast, cells infected with $M$. bovis had shrinkage, heavily stained cytoplasm, or condensation of nuclear chromatin and nuclear shrinkage at 12 and 24 hpi (Figure 4). Cellular damage was more apparent at $24 \mathrm{hpi}$ than earlier. Furthermore, to quantify morphological changes, cells in each well were quantified by measuring the average number of cells in a random selection of 5 fields per sample for each strain at 0,6 , 12 , and $24 \mathrm{hpi}$. Infected cells decreased significantly compared with cells in control groups at 12 and 24

Table 2. Release of lactate dehydrogenase ( $\mathrm{LDH}$; measured by optical density at $490 \mathrm{~nm}, \mathrm{OD}_{490 \mathrm{~mm}}$ ), as a marker of cytotoxicity, from infected bovine mammary epithelial cells varied among Mycobacterium bovis isolates

\begin{tabular}{llccc}
\hline Isolate & ST $^{1}$ & $\begin{array}{c}\text { Mean LDH } \\
\text { level }\left(\text { OD }_{490 \mathrm{~nm}}\right)\end{array}$ & SD & $P$-value \\
\hline NMH7 & ST173 & 1.672 & 0.081 & $0.000^{*}$ \\
NMH10 & ST173 & 1.601 & 0.027 & $0.000^{*}$ \\
HBCB01 & ST173 & 1.699 & 0.043 & $0.000^{*}$ \\
ShaanxiBTM01 & ST172 & 0.957 & 0.031 & $0.016^{*}$ \\
HBLFBTM01 & ST172 & 1.265 & 0.052 & $0.000^{*}$ \\
HBBDBTM & ST172 & 1.085 & 0.071 & $0.000^{*}$ \\
HBXTBTM & ST10 & 1.072 & 0.030 & $0.000^{*}$ \\
JZBTM & ST10 & 1.017 & 0.076 & $0.001^{*}$ \\
SD1901 & ST10 & 1.047 & 0.062 & $0.000^{*}$ \\
PG45 & ST17 & 1.065 & 0.060 & $0.000^{*}$ \\
Control & - & 0.758 & 0.058 & - \\
\hline
\end{tabular}

${ }^{1}$ Sequence type.

${ }^{*} P<0.05$ : compared with control group. 


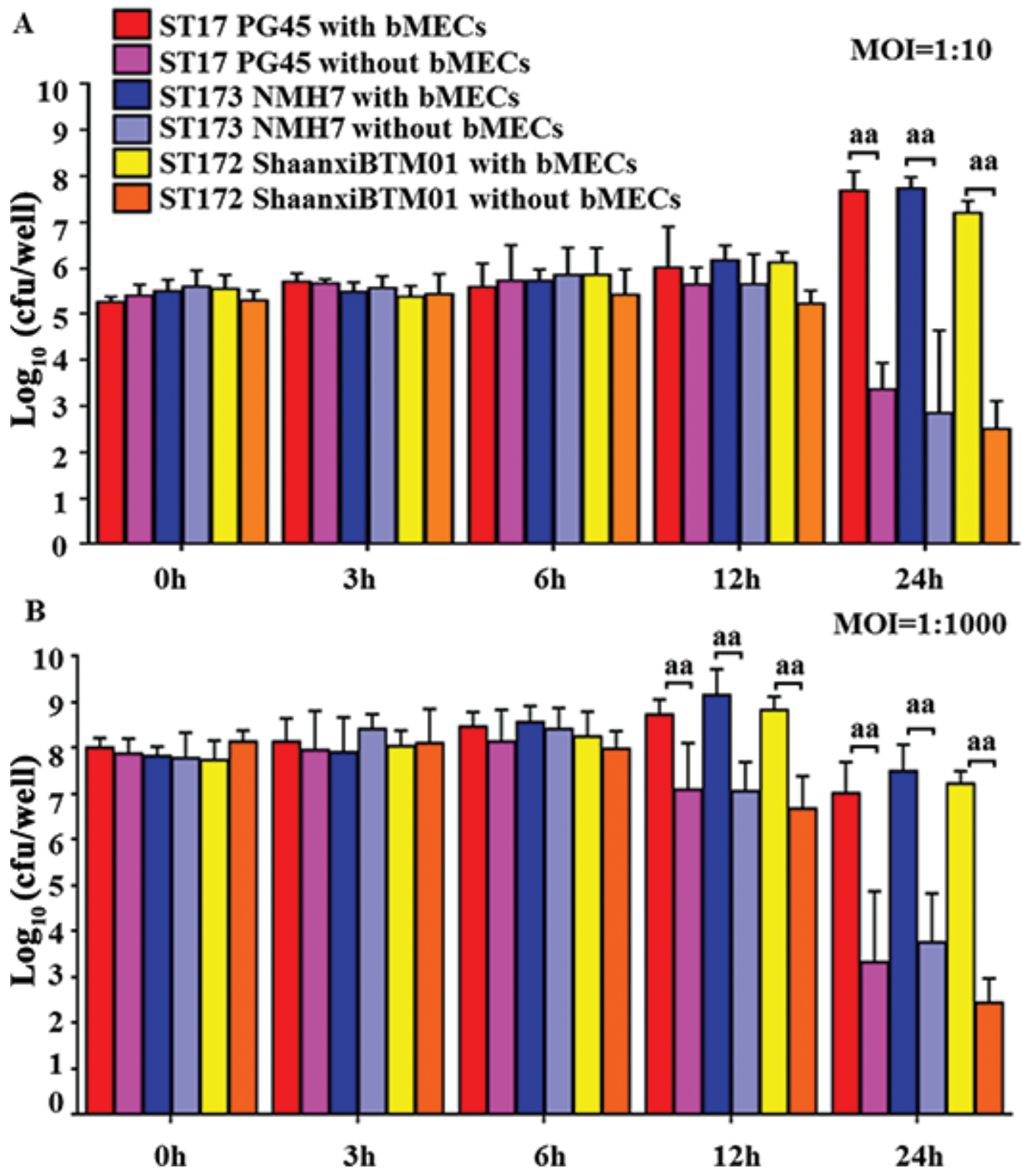

Figure 2. Infection model of Mycoplasma bovis with bovine mammary epithelial cells (bMEC) cells. To confirm the growth and survival pattern of $M$. bovis in the infected model, inocula of 3 strains were incubated with bMEC at multiplicities of infection (MOI) = 1:10 or 1:1,000, expressed as "with bMEC," whereas the corresponding inocula were incubated without bMEC, expressed as "without bMEC." Data are mean \pm SD of 3 independent experiments. Standard deviations of individual measurements indicated as bars. ${ }^{\text {aa }}$ Comparisons (at $P<0.01$ ) on $M$. bovis counts (CFU) between inocula with and without bMEC for the same strain.

hpi (Figure 4). Damage induced by the ST173 NMH7 strain was significantly more severe than that induced by ST172 ShaanxiBTM01 or ST17 PG45 (Figure 4). Concentrations of $M$. bovis in inocula prepared in the HE staining assays at an MOI of 1:1,000 were $2.86 \pm$ $1.38 \times 10^{8} \mathrm{cfu} / \mathrm{mL}$ for PG45, $3.16 \pm 1.83 \times 10^{8} \mathrm{cfu} / \mathrm{mL}$ for $\mathrm{NMH} 7$, and $3.75 \pm 1.16 \times 10^{8} \mathrm{cfu} / \mathrm{mL}$ for ShaanxiBTM01.
ROS Generation in bMEC Induced by M. bovis Infection

Concentrations of ROS in $M$. bovis-infected bMEC increased significantly over time $(P<0.01$ for $12 \mathrm{~h}$ or $24 \mathrm{~h}$; Figure 5). Although there was no significant difference among isolates in ROS concentrations at 12 h, ST173 NMH7 strain had induced higher ROS con- 
centrations than either ST17 PG45 or ST172 ShaanxiBTM01 by $24 \mathrm{~h}(P<0.001$ for ST173 NMH7 vs. ST17 PG45 or for ST173 NMH7 vs. ST172 ShaanxiBTM01).
The DCFH-DA-positive proportion of the positive control (bMEC treated with $500 \mu M \mathrm{H}_{2} \mathrm{O}_{2}$ for $24 \mathrm{~h}$ ) was $48.33 \pm 6.09 \%$, significantly greater than that of control
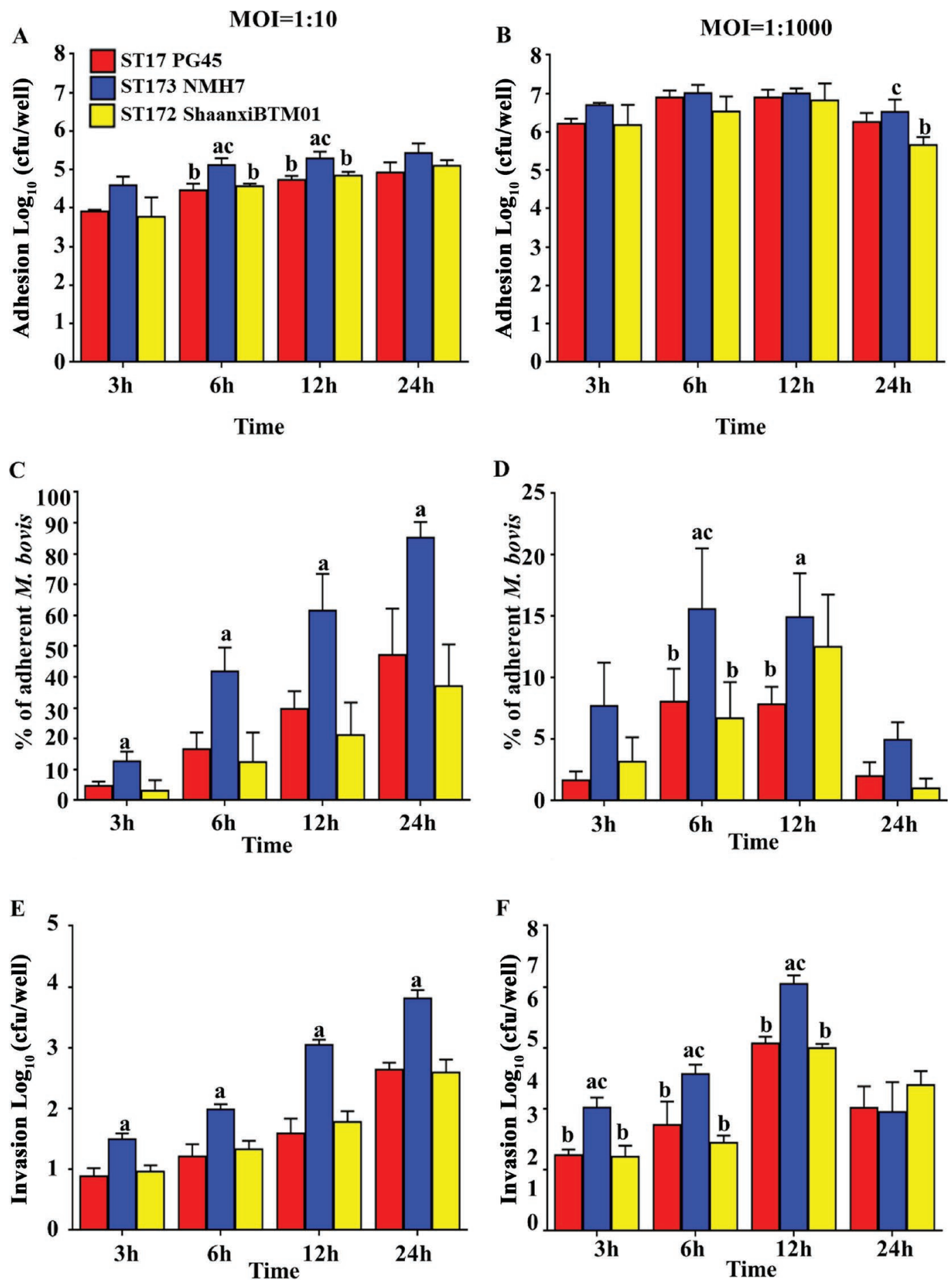

Figure 3. Adhesion of Mycoplasma bovis to bovine mammary epithelial cells (bMEC) and subsequent invasion. Number of adherent $M$. bovis relative to (A) multiplicity of infection (MOI) $=1: 10$ and $(\mathrm{B}) \mathrm{MOI}=1: 1,000$; percentage of adherent $M$. bovis relative to $(\mathrm{C}) \mathrm{MOI}=1: 10$ and (D) $\mathrm{MOI}=1: 1,000$; number of invasive $M$. bovis relative to $(\mathrm{E}) \mathrm{MOI}=1: 10$ and $(\mathrm{F}) \mathrm{MOI}=1: 1,000$. Data are mean $\pm \mathrm{SD}$ of 3 independent experiments. Letters indicate comparisons (at $P<0.05$ ) with ${ }^{\mathrm{a}} \mathrm{PG} 45,{ }^{\mathrm{b}} \mathrm{ST} 173 \mathrm{NMH7}$, and ${ }^{\mathrm{c}} \mathrm{ST} 172 \mathrm{ShaanxiBTM01.}$ 


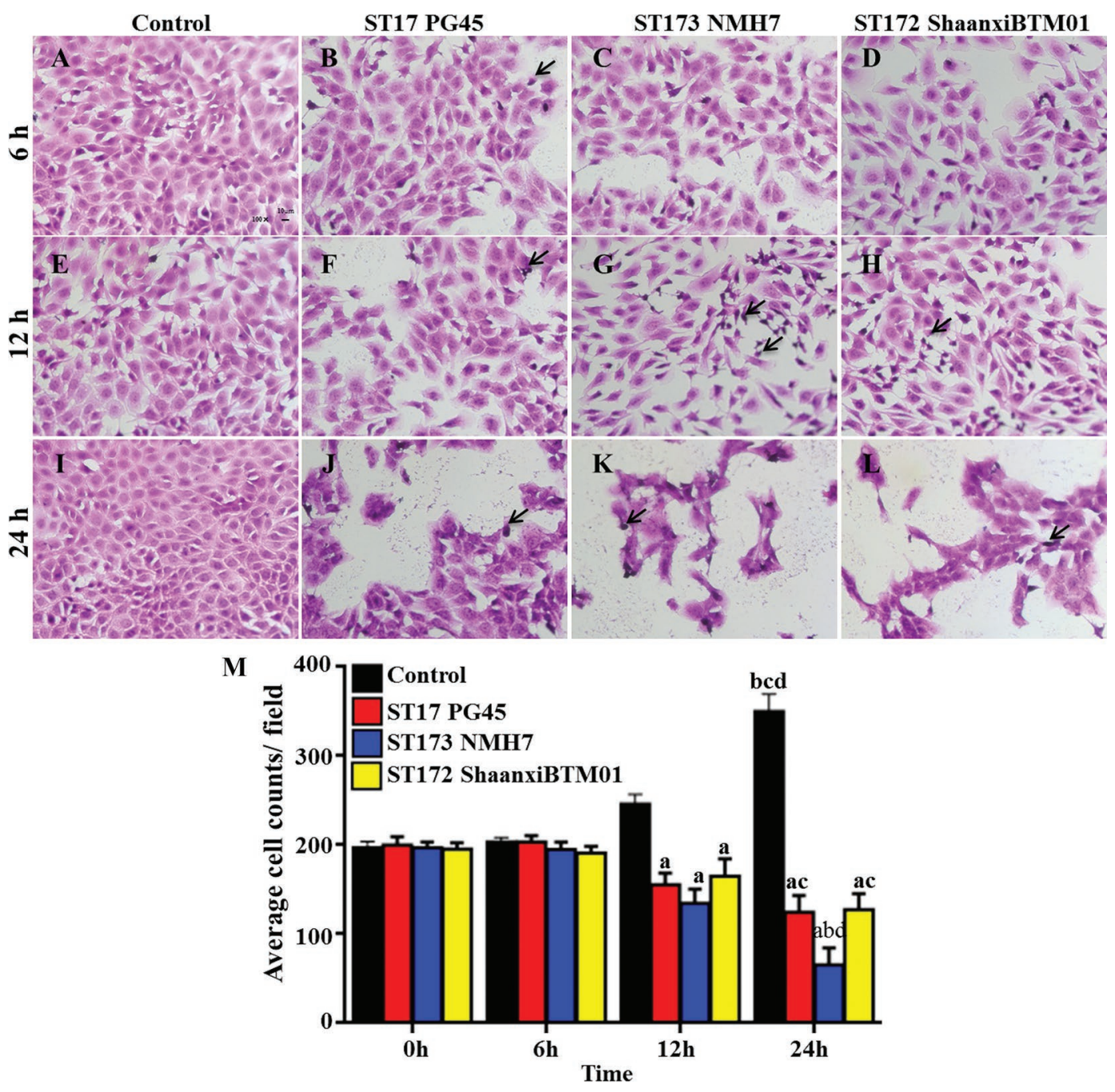

Figure 4. Morphological assessment of bovine mammary epithelial cells (bMEC) infected with Mycoplasma bovis based on optical microscopic examination $(100 \times)$ after hematoxylin-eosin staining. (A, E, I) Control at 6, 12, and $24 \mathrm{~h}$; (B, F, J) bMEC infected with ST17 PG45 at 6, 12, and 24 h; (C, G, K) bMEC infected with ST173 NMH7 at 6, 12, and 24 h; (D, H, L) bMEC infected with ST172 ShaanxiBTM01 at 6, 12 , and $24 \mathrm{~h}$. Black arrows indicate patho-morphological changes. Panel M shows average cell counts per field. Letters (a-d) indicate comparisons (at $P<0.05$ ) with (a) control group, (b) ST17 PG45, (c) ST173 NMH7, and (d) ST172 ShaanxiBTM01. Data are mean \pm SD of 3 independent experiments.

cells $(P<0.001)$. Concentrations of $M$. bovis in inocula prepared for ROS detections, apoptosis analysis, and protein and RNA extraction at at MOI of 1:1,000 were $3.27 \pm 0.99 \times 10^{8} \mathrm{cfu} / \mathrm{mL}$ for PG45, $3.16 \pm 1.42 \times 10^{8}$ $\mathrm{cfu} / \mathrm{mL}$ for $\mathrm{NMH} 7$, and $2.84 \pm 1.50 \times 10^{8} \mathrm{cfu} / \mathrm{mL}$ for ShaanxiBTM01.

\section{Apoptosis Generation in bMEC Induced by M. bovis Infection}

Proportions of apoptosis in $M$. bovis-infected bMEC increased significantly in a time-dependent manner (Figure 6). At $6 \mathrm{hpi}$, proportions of apoptosis were not significantly different between infected and control cells (uninfected cells). Proportions of apoptosis were marginally but significantly higher in infected cells at 12 hpi for ST173 NMH7 $(P=0.03)$, with a much larger difference at $24 \mathrm{hpi}$ for all strains $(P<$ 0.05). Furthermore, at that time, ST173 NMH7 strain had significantly more apoptosis than ST172 ShaanxiBTM01 $(P=0.036)$, with no significant difference among ST172 ShaanxiBTM01 and ST17 PG45. The apoptotic proportion of the positive control (bMEC treated with $500 \mu \mathrm{M} \mathrm{H} \mathrm{H}_{2} \mathrm{O}_{2}$ for $24 \mathrm{~h}$ ) was $10.08 \pm$ $2.00 \%$, significantly greater than that of control cells $(P=0.03)$. 

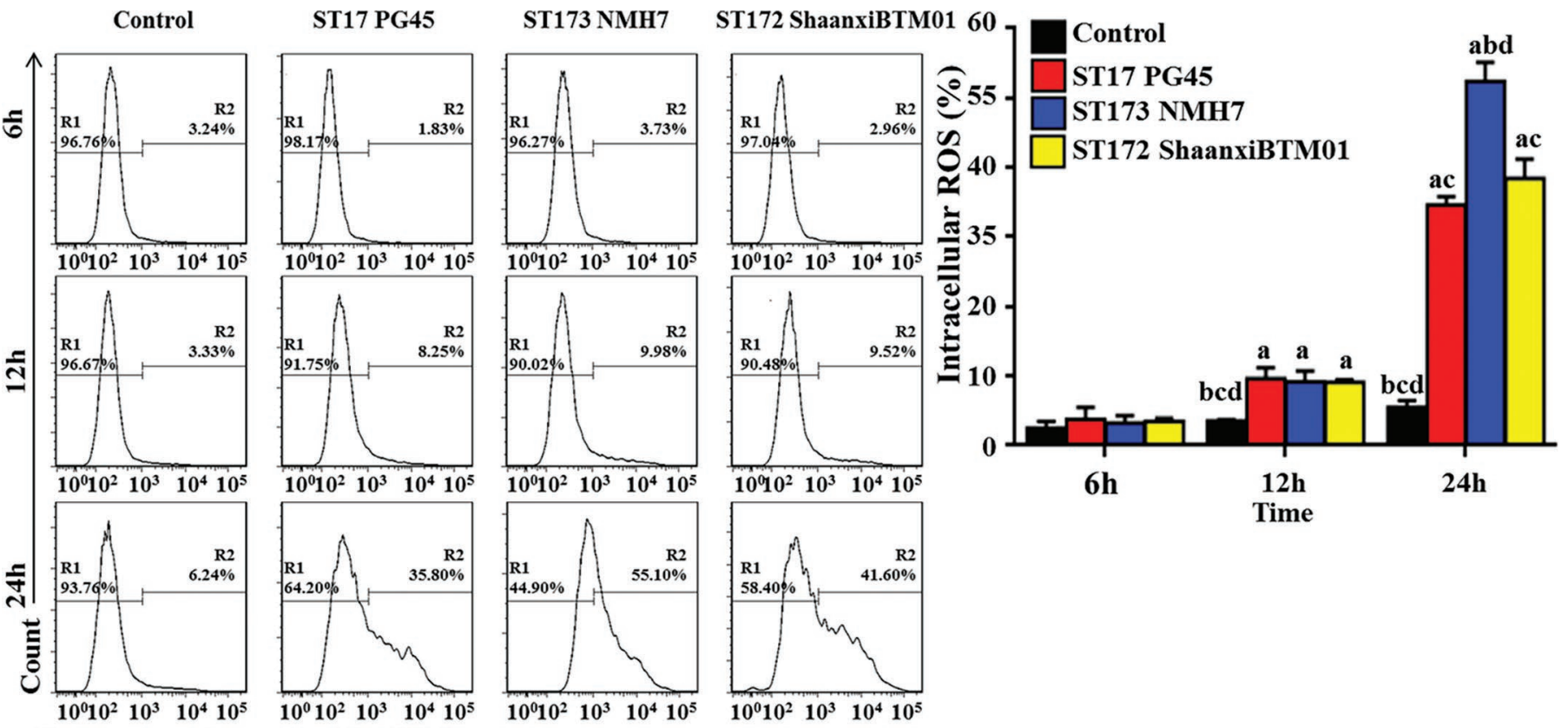

Fluorescence intensity of DCFH-DA
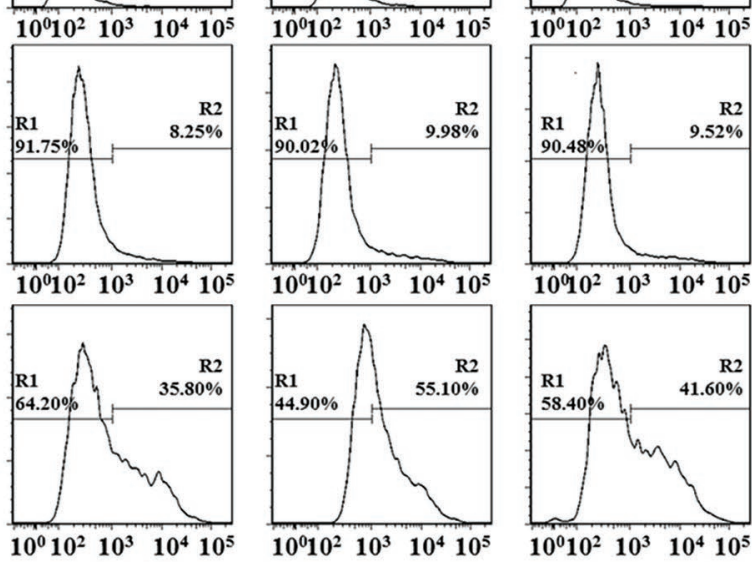

$10^{0} 10^{2} 10^{3} 10^{4} 10^{5}$
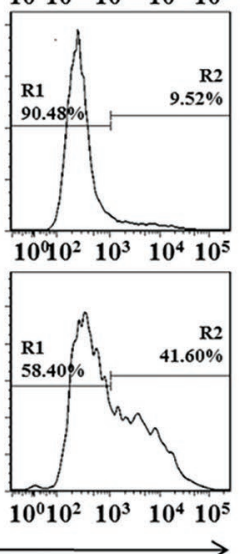

Time

Figure 5. Flow cytometry for production of reactive oxygen species (ROS) in bovine mammary epithelial cells (bMEC) infected with Mycoplasma bovis. R1 = percentage of 2'-7'dichlorofluorescin diacetate (DCFH-DA)-negative cells and R2 = percentage of DCFH-DA-positive cells. Data are mean $\pm \mathrm{SD}$ of 3 independent experiments. Letters $(\mathrm{a}-\mathrm{d})$ indicate comparisons $($ at $P<0.05)$ with (a) control group, (b) ST17 PG45, (c) ST173 NMH7, and (d) ST172 ShaanxiBTM01.

\section{Western Blot for Key Molecules in Apoptosis Signal Pathway}

Results of Western blot assay are presented in Figure 7A. For each strain, loading protein was quantified by GADPH as the internal reference. Ratios of Bax and Bcl-2 proteins increased after cells were infected (Figure 7B). Ratios of Bax and Bcl-2 of ST173 NMH7 strain were significantly higher $(P<0.05)$ than that of the other 2 strains at 12 and 24 hpi. Moreover, expression of cleaved caspase-3 was upregulated after infection (Figure 7A and C). Particularly, expression of cleaved caspase-3 in the ST173 NMH7 strain was the highest among 3 strains during all 3 time points $(P<0.05)$.

\section{Proinflammatory Cytokine and Chemokine mRNA}

The mRNA expression of IL1B,IL6,IL8, and TNFA in bMEC infected by $M$. bovis at MOI of 1:1,000 was determined by real-time quantitative PCR (Figure 8). Expression of $I L 1 B$ was significantly upregulated at 24 hpi for ST17 PG45 and ST173 NMH7 compared with uninfected cells $(P<0.05)$, with no significant change for cells infected by ST172 ShaanxiBTM01 strain. For TNFA and $I L 6$, there was a marginal, albeit significant $(P=0.012$ for IL6; $P=0.011$ for TNFA), upregulation in cells infected by ST173 NMH7 strain at $24 \mathrm{hpi}$, although there was no significant change for cells infected by ST17 PG45 or ST172 ShaanxiBTM01 strains. For $I L 8$, infection with ST173 NMH7 strain increased expression as early as 6 hpi $(P=0.029)$, followed by a continuous increase up to $24 \mathrm{hpi}(P<0.001)$. However, both ST17 PG45 and ST172 ShaanxiBTM01 strains induced later increases.

\section{ROS Scavenger Treatment}

In the absence of NAC, ROS concentrations in each group of infected bMEC were significantly higher $(P<$ 0.001) than those of control (Figure 9). However, for bMEC pretreated with NAC and subsequently infected with $M$. bovis, ROS concentrations decreased significantly $(P<0.001)$ compared with uninfected cells. In addition, we observed no significant difference in ROS concentrations between NAC pretreated and uninfected bMEC. Furthermore, the apoptosis proportion was significantly higher $(P<0.001)$ in each group of infected bMEC than in the control group when NAC was absent, whereas in bMEC pretreated with NAC and infected by $M$. bovis, apoptosis rates were significantly lower $(P<$ 0.001), similar to that of uninfected cells (Figure 9). Based on Western blotting, NAC decreased expression of cleaved caspase-3 in ST173 NMH7 M. bovis-infected bMEC (Figure 9). Concentrations of $M$. bovis in inocula 


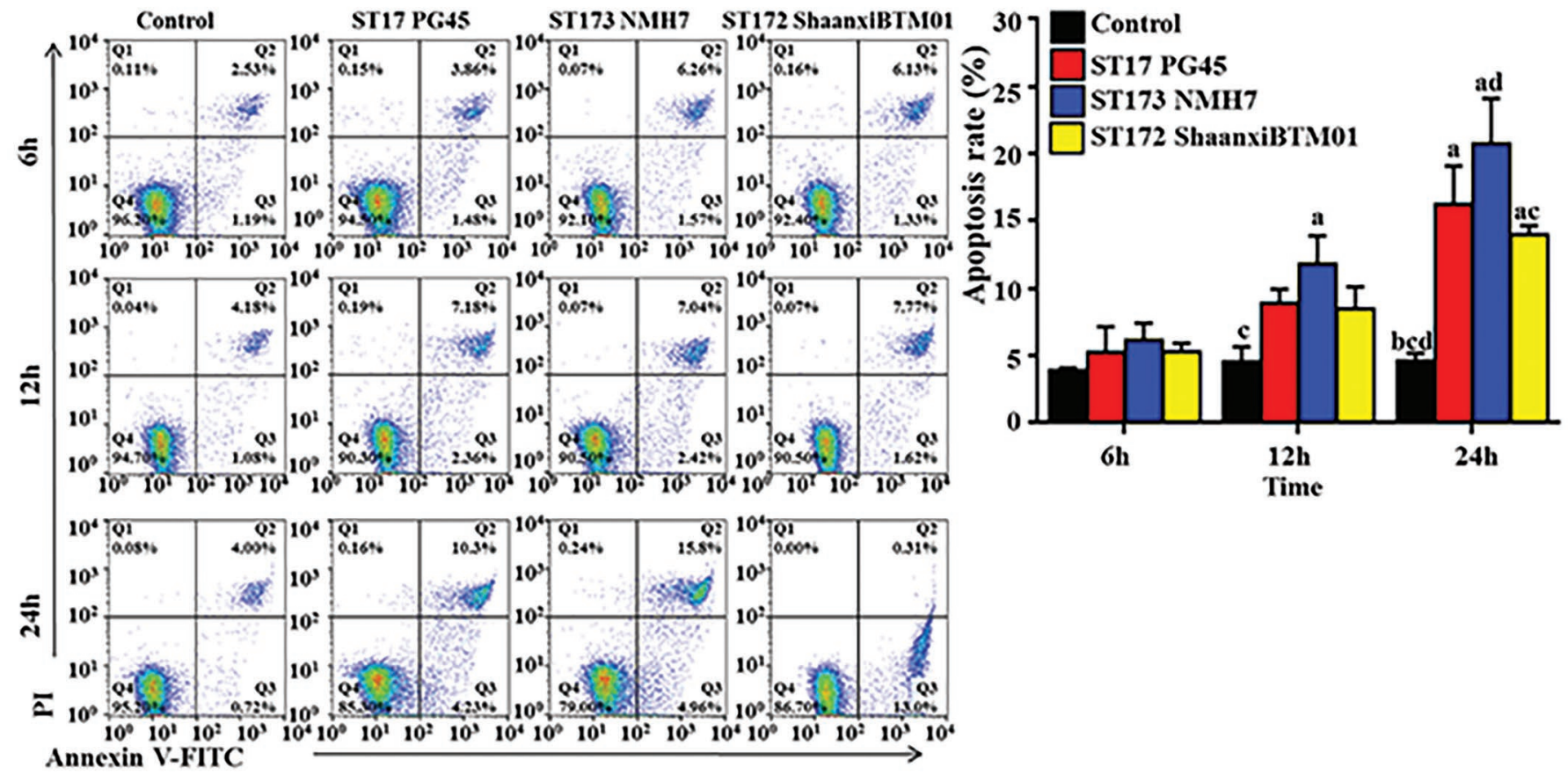

Figure 6. Flow cytometry assay for apoptosis of bovine mammary epithelial cells (bMEC) double stained by annexin V-FITC and propidium iodide (PI). Q1 = percentage of annexin V-negative, but PI-positive cells; Q2 = percentage of annexin V/PI double-positive cells (i.e., late apoptotic cells); Q3 = percentage of annexin V-positive, but PI-negative cells (i.e., early apoptotic cells); Q4 = percentage of annexin V/ PI double-negative cells (i.e., late live cells). The apoptosis proportion was determined as the sum of Q2 + Q3. Data are mean \pm SD of 3 independent experiments. Letters (a-d) indicate comparisons (at $P<0.05$ ) with (a) control group, (b) ST17 PG45, (c) ST173 NMH7, and (d) ST172 ShaanxiBTM01.

prepared in the ROS scavenger treatment at MOI of $1: 1,000$ were $2.61 \pm 1.11 \times 10^{8} \mathrm{cfu} / \mathrm{mL}$ for PG45, 2.82 $\pm 1.78 \times 10^{8} \mathrm{cfu} / \mathrm{mL}$ for NMH7, and $2.59 \pm 1.25 \times 10^{8}$ $\mathrm{cfu} / \mathrm{mL}$ for ShaanxiBTM01. The DCFH-DA-positive proportion of the bMEC treated with $\mathrm{H}_{2} \mathrm{O}_{2}(500 \mu M)$ was $23.27 \pm 3.75 \%$, significantly greater than the 4.91 $\pm 0.96 \%$ of the cells pretreated with NAC and then treated with $\mathrm{H}_{2} \mathrm{O}_{2}(500 \mu M)$. The apoptotic proportion of the bMEC treated with $\mathrm{H}_{2} \mathrm{O}_{2}(500 \mu M)$ was $24.68 \pm$ $7.61 \%$, significantly greater than the $4.61 \pm 0.93 \%$ of the cells pretreated with NAC and then treated with $\mathrm{H}_{2} \mathrm{O}_{2}(500 \mu M)$.

\section{DISCUSSION}

This is apparently the first report to characterize oxidative stress induced in bMEC by infection with $M$. bovis. There was evidence of activation through an intrinsic pathway of apoptosis, with variations among field isolates in their capability to damage bMEC.

An in vitro model using bMEC was established, with an LDH assay used to quantify cell damage. In that regard, $\mathrm{LDH}$ is a stable cytoplasmic enzyme in healthy cells but rapidly released into cell culture supernatant when cells are damaged by, for example, apoptosis, necrosis, and so on. Hence, LDH is a marker of cell death (Specian et al., 2016). In this study, we observed significant increase in LDH release at 12 and $24 \mathrm{~h}$ after infection with MOI of 1:1,000. Therefore, $M$. bovis at high MOI damaged bMEC cultured in vitro. However, at MOI of 1:10 and 1:100, there was no significant difference between infected and uninfected bMEC. Similarly, in a previous study, M. bovis at MOI of 1:1.3 and 1:9 did not induce cytotoxicity in bMEC. In a study involving intramammary $M$. bovis infection, numbers of $M$. bovis in milk samples increased more than $8 \log _{10}$ $\mathrm{cfu} / \mathrm{mL}$ at $108 \mathrm{hpi}$, followed by a plateau with maximal numbers of $M$. bovis $\left(9.61 \pm 0.16 \log _{10} \mathrm{cfu} / \mathrm{mL}\right)$ at 192 hpi (Kauf et al., 2007). Therefore, the MOI of 1:1,000 (equal to $\sim 8 \log _{10} \mathrm{cfu} / \mathrm{mL}$ ) in this study was in the clinical range of mycoplasma loading quantity.

Cell death following infection was confirmed by morphological changes. Infection with $M$. bovis resulted in many morphologic changes consistent with cell death, including shrinkage, loss of cell integrity, heavily stained cytoplasm, and chromatin margination. Interactions between $M$. bovis and host cells were initiated by adhesion and invasion of $M$. bovis. Percentages of adherent $M$. bovis at $3 \mathrm{hpi}$ were similar to those in a previous study in which an adhesion assay was performed at $2 \mathrm{~h}$ 
(Josi et al., 2018). However, adhesion and invasion had curvilinear patterns, peaking $12 \mathrm{hpi}$ at MOI of 1:1,000 in this study. We inferred that bMEC underwent saturation at $12 \mathrm{~h}$ and MOI of 1:1,000. The percentage of adherent $M$. bovis decreased at $24 \mathrm{~h}$, which was attributed to cell death and confirmed by HE staining.

Although there was increased ROS generation in bMEC at $24 \mathrm{~h}$ after infection with $M$. bovis at high MOI, this increase was mitigated by NAC. The level of oxidative stress is one of the most important indicators of physiological state. Free radicals induce cell damage, increasing the risk of developing mastitis (Bouwstra et al., 2010). Whether field isolates vary in their ability to cause clinical severity in vivo remains unclear; however, it is generally recognized that pathogenicity of $M$. bovis depends not only on the strain, but also on the host state (Calcutt et al., 2018). Combined with current findings, we inferred that cows with elevated ROS concentrations due to various stressors (e.g., nutrition, environmental conditions, long distance transport, or presence of other pathogens) may be predisposed to have substantial clinical signs or lesions. Further stud- ies on oxidative stress induced by $M$. bovis in vivo are needed.

Although apoptosis is an important cell death pattern contributing to mastitis development, before this study, it was uncertain whether $M$. bovis could induce apoptosis in bMEC. In this study, apoptosis was detected by flow cytometry using annexin V-FITC/PI dual staining; in bMEC infected with $M$. bovis at MOI of 1:1,000, we observed significant increases in apoptosis rates 24 hpi. In a previous study, bMEC were infected with $M$. bovis at MOI ranging from 1:1.3 and 1:9, and no apparent increase in apoptosis was observed based on caspase- $3 / 7$ activity luminescent assay. Therefore, we inferred that the bMEC response to $M$. bovis infection is highly dependent on MOI. Nuclease activity of $M$. bovis cell lysates and membrane nuclease MBOVPG45_0215, indicating potential pathogenicity, were detected using a DNA digestion assay (Sharma et al., 2015). Perhaps the $M$. bovis nuclease damaged DNA of bMEC and increased ROS, resulting in oxidative stress, which initiated apoptosis (Malhotra and Kaufman, 2007). Based on apoptosis of bMEC, we inferred that $M$. bovis may
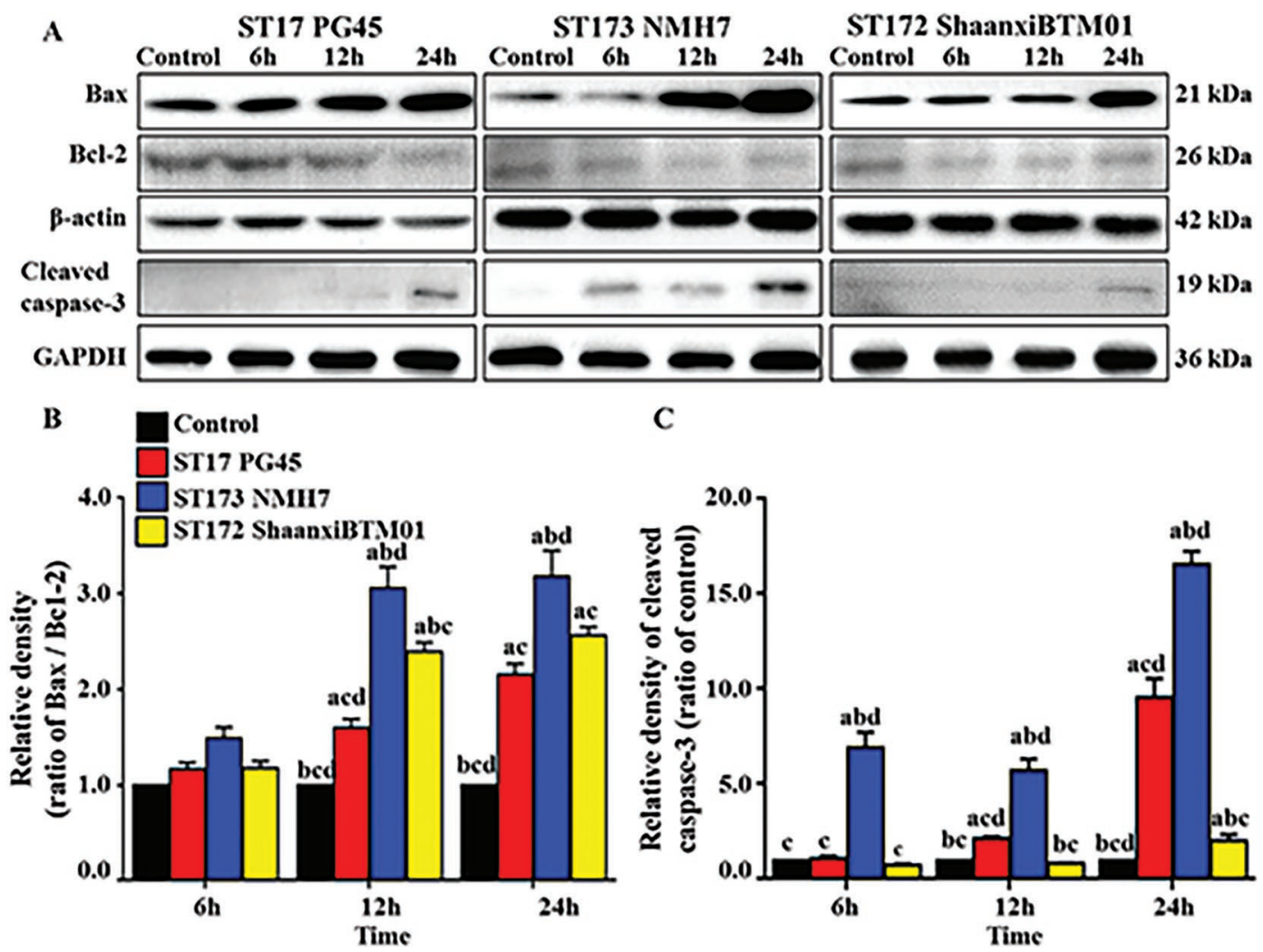

C

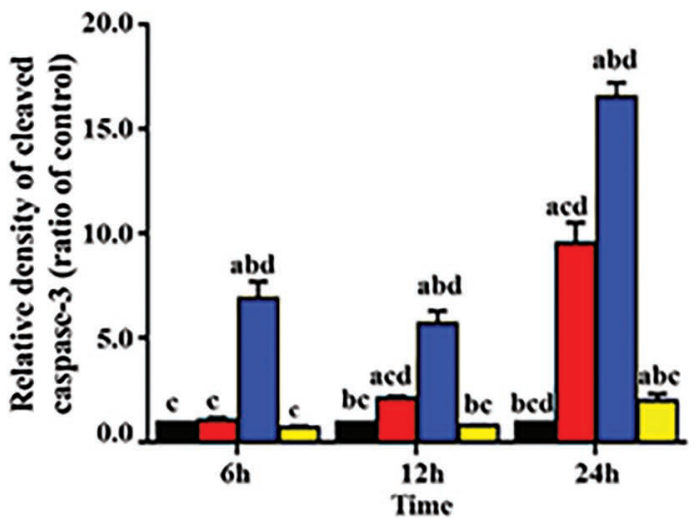

Figure 7. Protein levels of Bax, Bcl-2, and cleaved caspase 3 in bovine mammary epithelial cells (bMEC) infected with Mycoplasma bovis. (A) Western blotting results of Bax, Bcl-2, and cleaved caspase 3; (B) change in ratio of Bax and Bcl-2; (C) change in cleaved caspase 3. Data are mean $\pm \mathrm{SD}$ of 3 independent experiments. Letters (a-d) indicate comparisons (at $P<0.05$ ) with (a) control group, (b) ST17 PG45, (c) ST173 NMH7, and (d) ST172 ShaanxiBTM01. 

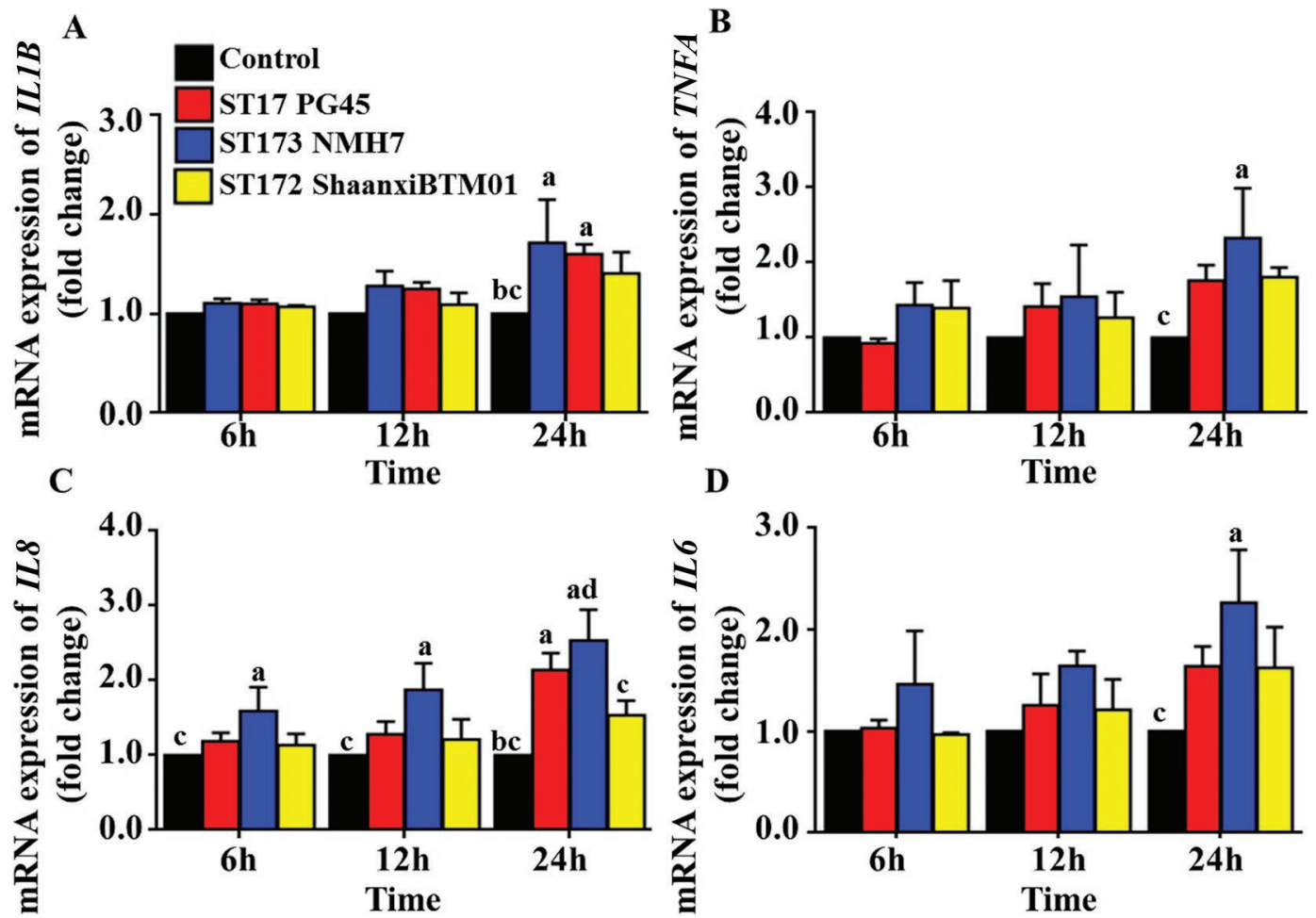

Figure 8. Expressions of cytokine mRNA in bovine mammary epithelial cells (bMEC) infected with Mycoplasma bovis. mRNA expression of (A) IL1B, (B) TNFA, (C) IL8, and (D) IL6. Data are mean \pm SD of 3 independent experiments. Letters (a-d) indicate comparisons (at $P<$ 0.05) with (a) control group, (b) ST17 PG45, (c) ST173 NMH7, and (d) ST172 ShaanxiBTM01.

cause tissue damage in infected udders, contributing to increased SCC in milk.

In mammalian cells, mitochondria are the main source of ROS and closely linked to apoptosis (Sinha et al., 2013). In this study, changes in ratio of Bax and Bcl-2 and in cleaved caspase-3 implicated mitochondria-dependent pathways in apoptosis. Bax is a pro-apoptotic protein located in the outer membrane of mitochondria, whereas Bcl-2 is an inhibitor of apoptosis. An increased Bax/Bcl-2 ratio results in mitochondrial permeability transition, leading to release of cytochrome C into the cytoplasm (Sinha et al., 2013). Caspase-3 is activated by a cascade reaction, including apoptosome formation, consisting of caspase- 9 and apf-1 recruited by cytochrome C (Shahid et al., 2020), with activation of the apoptotic pathway. In addition, pretreatment with NAC, a potent ROS scavenger, significantly decreased ROS concentrations, followed by a decrease in expression of cleaved caspase- 3 protein and decreased apoptosis rates. Therefore, we concluded that ROS generation induced by $M$. bovis infection triggered apoptosis of bMEC.

Cytokines produced by epithelial cells have important roles on innate immunity in udders (Rainard and Riollet, 2006). In the present study, IL-1 $\beta$, IL-6, TNF- $\alpha$, and IL-8 were increased at 24 hpi for ST173 NMH7, whereas cytokine expression was not significantly altered in response to ST172 ShaanxiBTM01. Therefore, we inferred that the ability to alter cytokine mRNA expressions varied among isolates. Interleukin-1 $\beta$, an important proinflammatory cytokine, was reported to be triggered by ROS through activation of the NLRP3 inflammasome in epithelial cells (Onat et al., 2019). Apoptosis is promoted by TNF- $\alpha$ but blocked by IL- 6 (Kiraz et al., 2016; Chen et al., 2018). Apoptosis of bMEC is the end-stage outcome of $M$. bovis infection. Increased expression of $I L 8 \mathrm{mRNA}$ in this study was consistent with previous data collected both in vitro and in vivo (Kauf et al., 2007; Zbinden et al., 2015). Interleukin- 8 mediates inflammation by regulating the influx of neutrophils from the blood to udder tissue. The extent of modulation of IL-1 $\beta$, IL- 6 , TNF- $\alpha$, and IL-8 in bMEC varied among $M$. bovis strains, with ST172 ShaanxiBTM01 having limited ability to induce inflammation in bMEC.

The bMEC infection model described here was used to assess adhesion differences among $M$. bovis mutants (Josi et al., 2019). In this study, cell damage-inducing capability varied among isolates. In the LDH assay, 3 isolates with ST173 induced the greatest LDH concen- 

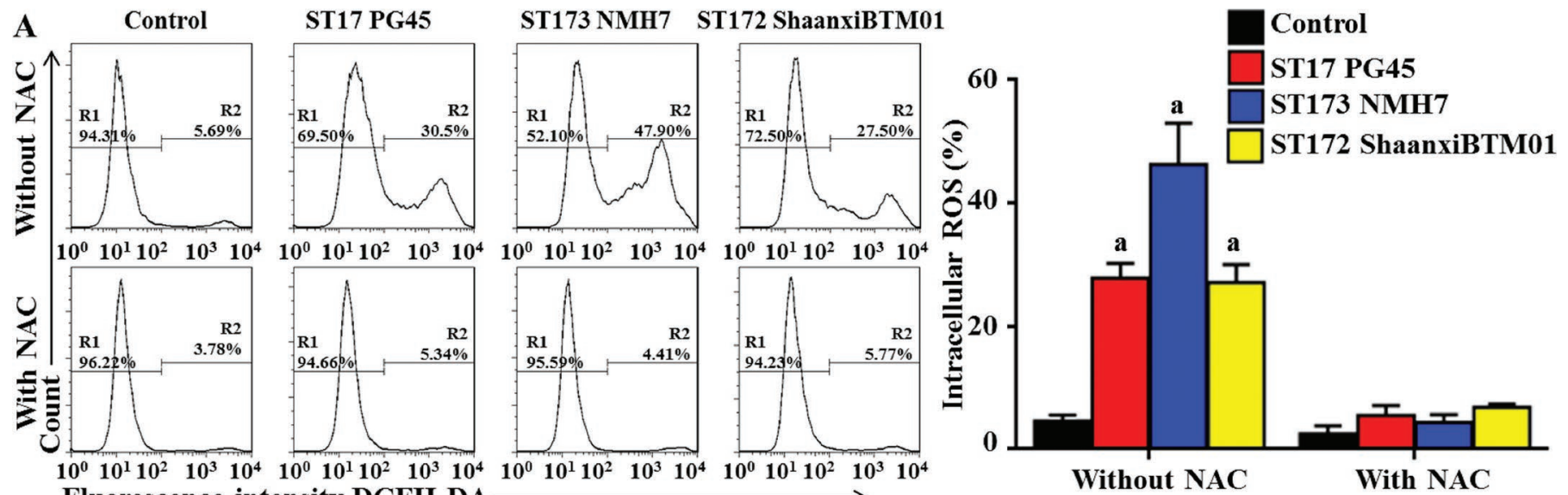

Fluorescence intensity DCFH-DA-
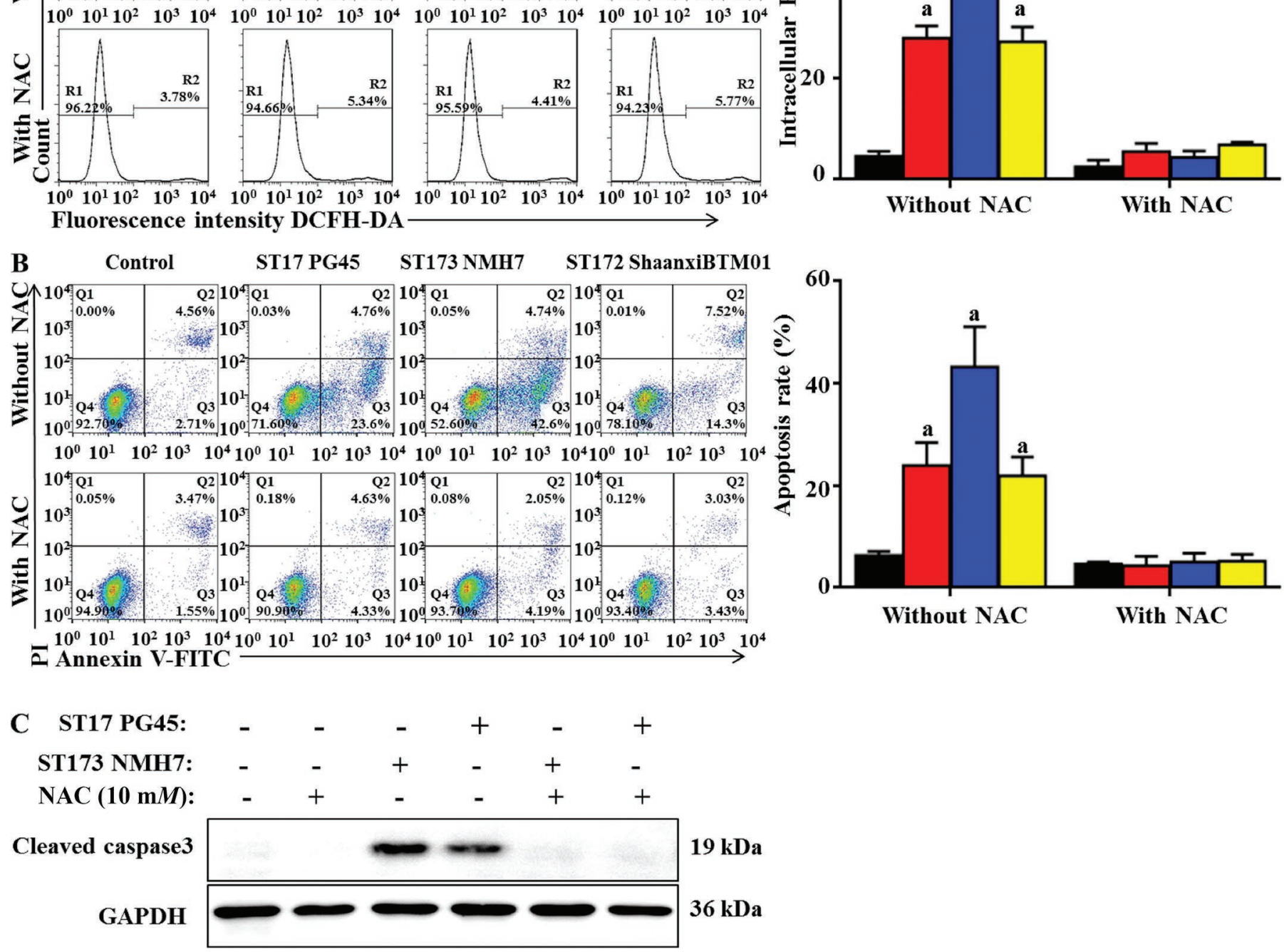

Figure 9. Effect of $N$-acetyl-L-cysteine (NAC) on bovine mammary epithelial cell (bMEC) response to Mycoplasma bovis. (A) Reactive oxygen species (ROS) assay of the effect of NAC on the bMEC response to $M$. bovis; $\mathrm{R} 1=$ percentage of $2^{\prime}-7^{\prime}$ dichlorofluorescin diacetate (DCFHDA)-negative cells; R2 = percentage of DCFH-DA-positive cells. (B) Apoptosis assay of the effect of NAC on the bMEC response to M. bovis; Q1 = percentage of annexin V-negative, propidium iodide (PI)-positive cells (i.e., necrotic cells); Q2 = percentage of annexin V/PI double-positive cells (i.e., late apoptotic cells); Q3 = percentage of annexin V-positive, but PI-negative cells (i.e., early apoptotic cells); Q4 = percentage of annexin V/PI double-negative cells (i.e., late live cells); the apoptosis proportion was determined as the sum of Q2 + Q3. (C) Western blotting assay showing the effect of NAC on caspase 3 on the bMEC response to $M$. bovis. Data are mean \pm SD of 3 independent experiments. Letter (a) indicates comparisons (at $P<0.05$ ) with control group. FITC $=$ fluorescein isothiocyanate.

trations, followed by ST172 and ST17 PG45. Consequently, 1 ST173 isolate (NMH7 ST173) was randomly selected to be used in the following experiments. In addition, ST172 ShaanxiBTM01 strain was selected randomly among isolates with ST172 and ST10 that were clustered into the same clonal complex. Adhesion, invasion, apoptosis, and ROS inducing capabilities were compared among ST173 NMH7, ST172 ShaanxiBTM01, and ST17 PG45; ST173 NMH7 had significantly higher pathogenic capacity.

The 2 main limitations of this study were the use of the MAC-T cell line and the limited number of isolates tested. The MAC-T cell line may have certain characteristics different from primary cultures of bMEC in 
terms of the response to $M$. bovis infection. Regardless, the MAC-T cell line provided an easily standardized cell model for ROS and apoptosis analysis in M. bovis infection. Although field isolates varied in their ability to cause cell damage on MAC-T cell line in vitro, we inferred that these differences were associated with their genotypes. Consequently, trials with primary bMEC are needed to verify the ability of $M$. bovis infection to increase ROS and apoptosis and to make detailed assessments of genomes and in vivo pathogenicity.

\section{CONCLUSIONS}

We concluded that $M$. bovis induced ROS generation and apoptosis in bMEC, based on an initial study using a MAC-T cell line, providing insights into the pathogenicity of mycoplasma mastitis. Based on our cell model, we detected differences among strains regarding their in vitro pathogenicity. Further studies are planned to test the pathogenicity of $M$. bovis on primary cultures of bMEC and to explore specific mechanisms involved in $M$. bovis virulence and the role of oxidative stress in mycoplasma mastitis.

\section{ACKNOWLEDGMENTS}

This study was financially supported by Ningxia Key R\&D Project (No. 2019BBF02027), Hebei Key R\&D Project (19226607D), the National Natural Science Foundation of China (Beijing; No. 31772813, 31660730 and 31572587), the High-end Foreign Experts Recruitment Program (No. GDT20171100013), and the National Dairy Industry and Technology System (Beijing, China; CARS-36). The authors declare no competing interests.

\section{REFERENCES}

Bouwstra, R. J., M. Nielen, J. R. Newbold, E. H. Jansen, H. F. Jelinek, and T. van Werven. 2010. Vitamin E supplementation during the dry period in dairy cattle. Part II: Oxidative stress following vitamin E supplementation may increase clinical mastitis incidence postpartum. J. Dairy Sci. 93:5696-5706. https://doi.org/10.3168/ jds.2010-3161.

Bürki, S., V. Gaschen, M. H. Stoffel, A. Stojiljkovic, J. Frey, K. Kuehni-Boghenbor, and P. Pilo. 2015. Invasion and persistence of $M y-$ coplasma bovis in embryonic calf turbinate cells. Vet. Res. 46:53. https://doi.org/10.1186/s13567-015-0194-z.

Calcutt, M. J., I. Lysnyansky, K. Sachse, L. K. Fox, R. A. J. Nicholas, and R. D. Ayling. 2018. Gap analysis of Mycoplasma bovis disease, diagnosis and control: An aid to identify future development requirements. Transbound. Emerg. Dis. 65:91-109. https://doi.org/ 10.1111/tbed.12860.

Chen, Y., J. Liu, P. Lv, J. Gao, M. Wang, and Y. Wang. 2018. IL-6 is involved in malignancy and doxorubicin sensitivity of renal carcinoma cells. Cell Adh. Migr. 12:28-36. https://doi.org/10.1080/ 19336918.2017.1307482.
Fox, L. K. 2012. Mycoplasma mastitis: Causes, transmission, and control. Vet. Clin. North Am. Food Anim. Pract. 28:225-237. https:/ /doi.org/10.1016/j.cvfa.2012.03.007.

Gu, X., Z. Wang, J. Gao, D. Han, L. Zhang, P. Chen, G. Luo, and B. Han. 2019. SIRT1 suppresses p53-dependent apoptosis by modulation of p21 in osteoblast-like MC3T3-E1 cells exposed to fluoride. Toxicol. In Vitro 57:28-38. https://doi.org/10.1016/j.tiv.2019.02 .006 .

Guo, W., J. Liu, J. Sun, Q. Gong, H. Ma, X. Kan, Y. Cao, J. Wang, and S. Fu. 2020. Butyrate alleviates oxidative stress by regulating NRF2 nuclear accumulation and H3K9/14 acetylation via GPR109A in bovine mammary epithelial cells and mammary glands. Free Radic. Biol. Med. 152:728-742. https://doi.org/10 .1016/j.freeradbiomed.2020.01.016.

Jimbo, S., M. Suleman, T. Maina, T. Prysliak, M. Mulongo, and J. Perez-Casal. 2017. Effect of Mycoplasma bovis on bovine neutrophils. Vet. Immunol. Immunopathol. 188:27-33. https://doi.org/ 10.1016/j.vetimm.2017.04.011.

Josi, C., S. Bürki, A. Stojiljkovic, O. Wellnitz, M. H. Stoffel, and P. Pilo. 2018. Bovine epithelial in vitro infection models for Mycoplasma bovis. Front. Cell. Infect. Microbiol. 8:329. https://doi.org/ 10.3389/fcimb.2018.00329.

Josi, C., S. Bürki, S. Vidal, E. Dordet-Frisoni, C. Citti, L. Falquet, and P. Pilo. 2019. Large-scale analysis of the Mycoplasma bovis genome identified non-essential, adhesion- and virulence-related genes. Front. Microbiol. 10:2085. https://doi.org/10.3389/fmicb .2019 .02085 .

Kauf, A. C., R. F. Rosenbusch, M. J. Paape, and D. D. Bannerman. 2007. Innate immune response to intramammary Mycoplasma bovis infection. J. Dairy Sci. 90:3336-3348. https://doi.org/10.3168/ jds.2007-0058.

Kiraz, Y., A. Adan, M. K. Yandim, and Y. Baran. 2016. Major apoptotic mechanisms and genes involved in apoptosis. Tumour Biol. 37:8471-8486. https://doi.org/10.1007/s13277-016-5035-9.

Liu, G., Y. Liu, T. Ali, M. Ferreri, J. Gao, W. Chen, J. Yin, J. Su, S. Fanning, and B. Han. 2015. Molecular and phenotypic characterization of Aerococcus viridans associated with subclinical bovine mastitis. PLoS One 10:e0125001. https://doi.org/10.1371/journal pone.0125001.

Liu, Y., S. Xu, M. Li, M. Zhou, W. Huo, J. Gao, G. Liu, P. J. Kastelic, and B. Han. 2020. Molecular characteristics and antibiotic susceptibility profiles of Mycoplasma bovis associated with mastitis on dairy farms in China. Prev. Vet. Med. 182:105106. https://doi.org/ 10.1016/j.prevetmed.2020.105106.

Maina, T., T. Prysliak, and J. Perez-Casal. 2019. Mycoplasma bovis delay in apoptosis of macrophages is accompanied by increased expression of anti-apoptotic genes, reduced cytochrome C translocation and inhibition of DNA fragmentation. Vet. Immunol. Immunopathol. 208:16-24. https://doi.org/10.1016/j.vetimm.2018.12 .004 .

Malhotra, J. D., and R. J. Kaufman. 2007. Endoplasmic reticulum stress and oxidative stress: A vicious cycle or a double-edged sword? Antioxid. Redox Signal. 9:2277-2294. https://doi.org/10 .1089 /ars.2007.1782.

National Mastitis Council. 2017. Laboratory Handbook on Bovine Mastitis. NMC Inc., Madison, WI.

Nicholas, R. A., L. K. Fox, and I. Lysnyansky. 2016. Mycoplasma mastitis in cattle: To cull or not to cull. Vet. J. 216:142-147. https:// doi.org/10.1016/j.tvjl.2016.08.001.

Onat, U. I., A. D. Yildirim, Ö. Tufanli, I. Çimen, B. Kocatürk, Z. Veli, S. M. Hamid, K. Shimada, S. Chen, J. Sin, P. K. Shah, R. A. Gottlieb, M. Arditi, and E. Erbay. 2019. Intercepting the lipid-induced integrated stress response reduces atherosclerosis. J. Am. Coll. Cardiol. 73:1149-1169. https://doi.org/10.1016/j.jacc.2018.12.055.

Rainard, P., and C. Riollet. 2006. Innate immunity of the bovine mammary gland. Vet. Res. 37:369-400. https://doi.org/10.1051/vetres: 2006007.

Register, K. B., I. Lysnyansky, M. D. Jelinski, W. D. Boatwright, M. Waldner, D. O. Bayles, P. Pilo, and D. P. Alt. 2020. Comparison of two multilocus sequence typing schemes for Mycoplasma bovis and 
revision of the PubMLST reference method. J. Clin. Microbiol. 58:e00283-e20. https://doi.org/10.1128/JCM.00283-20.

Ruegg, P. L. 2017. A 100-year review: Mastitis detection, management, and prevention. J. Dairy Sci. 100:10381-10397. https://doi .org/10.3168/jds.2017-13023.

Schott, C., H. Cai, L. Parker, K. G. Bateman, and J. L. Caswell. 2014. Hydrogen peroxide production and free radical-mediated cell stress in Mycoplasma bovis pneumonia. J. Comp. Pathol. 150:127-137. https://doi.org/10.1016/j.jcpa.2013.07.008.

Shahid, M., E. R. Cobo, L. Chen, P. A. Cavalcante, H. W. Barkema, J. Gao, S. Xu, Y. Liu, C. G. Knight, J. P. Kastelic, and B. Han. 2020. Prototheca zopfii genotype II induces mitochondrial apoptosis in models of bovine mastitis. Sci. Rep. 10:698. https://doi.org/ 10.1038/s41598-020-57645-Z.

Sharma, S., K. A. Tivendale, P. F. Markham, and G. F. Browning. 2015. Disruption of the membrane nuclease gene (MBOVPG45_0215) of Mycoplasma bovis greatly reduces cellular nuclease activity. J. Bacteriol. 197:1549-1558. https://doi.org/10.1128/JB.00034-15.

Sinha, K., J. Das, P. B. Pal, and P. C. Sil. 2013. Oxidative stress: the mitochondria-dependent and mitochondria-independent pathways of apoptosis. Arch. Toxicol. 87:1157-1180. https://doi.org/10 $.1007 / \mathrm{s} 00204-013-1034-4$.
Specian, A. F. L., J. M. Serpeloni, K. Tuttis, D. L. Ribeiro, H. L. Cilião, E. A. Varanda, M. Sannomiya, W. Martinez-Lopez, W. Vilegas, and I. M. S. Cólus. 2016. LDH, proliferation curves and cell cycle analysis are the most suitable assays to identify and characterize new phytotherapeutic compounds. Cytotechnology 68:2729-2744. https://doi.org/10.1007/s10616-016-9998-6.

van der Merwe, J., T. Prysliak, and J. Perez-Casal. 2010. Invasion of bovine peripheral blood mononuclear cells and erythrocytes by Mycoplasma bovis. Infect. Immun. 78:4570-4578. https://doi.org/ 10.1128/IAI.00707-10.

Vanden Bush, T. J., and R. F. Rosenbusch. 2002. Mycoplasma bovis induces apoptosis of bovine lymphocytes. FEMS Immunol. Med. Microbiol. 32:97-103. https://doi.org/10.1111/j.1574-695X.2002 .tb00540.x.

Wiggins, M. C., A. R. Woolums, D. J. Hurley, S. Sanchez, D. T. Ensley, and D. Donovan. 2011. The effect of various Mycoplasma bovis isolates on bovine leukocyte responses. Comp. Immunol. Microbiol. Infect. Dis. 34:49-54. https://doi.org/10.1016/j.cimid.2010.02.001.

Zbinden, C., P. Pilo, J. Frey, R. M. Bruckmaier, and O. Wellnitz. 2015. The immune response of bovine mammary epithelial cells to live or heat-inactivated Mycoplasma bovis. Vet. Microbiol. 179:336-340. https://doi.org/10.1016/j.vetmic.2015.07.007. 